Research Article

\title{
Experimental Research on Damping Effect of Double-Layer Tuned Mass Damper for High-Rise Structure
}

\author{
Botan Shen, ${ }^{1}$ Jin Wang $\mathbb{D},{ }^{1}$ Weibing Xu $\mathbb{D},{ }^{1,2}$ Yanjiang Chen, ${ }^{1}$ Weiming Yan, \\ Jianhui Huang, ${ }^{1}$ and Zhenyun Tang ${ }^{2}$ \\ ${ }^{1}$ Beijing Key Laboratory of Earthquake Engineering and Structure Retrofit, Beijing University of Technology, \\ Beijing 100124, China \\ ${ }^{2}$ The Key Laboratory of Urban Security and Disaster Engineering of Ministry of Education, Beijing University of Technology, \\ Beijing 100124, China
}

Correspondence should be addressed to Jin Wang; wangin418@126.com

Received 19 September 2021; Revised 4 November 2021; Accepted 10 November 2021; Published 2 December 2021

Academic Editor: Jingxuan Wang

Copyright (c) 2021 Botan Shen et al. This is an open access article distributed under the Creative Commons Attribution License, which permits unrestricted use, distribution, and reproduction in any medium, provided the original work is properly cited.

\begin{abstract}
A double-layer tuned mass damper (DTMD) has advantages of wide damping frequency band and strong robustness. At present, there is a lack of seismic design methods for high-rise structures based on DTMDs. In this study, a DTMD parameter optimisation method was proposed, with the objective of minimising the peak displacement response of a first $\mathrm{N}$-order vibration modal with a vibration mass participation factor of $85 \%$. Then, a scale model of a high-rise structure was fabricated, along with a corresponding DTMD. Different types of excitations were chosen to clarify the dynamic responses of the model with and without the DTMD, including Site-II ground motions, long-period (LP) ground motions without pulses, and near-fault pulse-type (NFPT) ground motions. The results indicate that the dynamic responses of high-rise structures under LP and NFPT ground motions are much greater than those under Site-II ground motions. The DTMD can effectively reduce the absolute displacement response, acceleration response, and strain response at the top floor of the test model. However, the DTMD has a time delay in providing the damping effect. A smaller damping ratio between the upper TMD and the controlled structure will lead to a more significant damping effect for the DTMD.
\end{abstract}

\section{Introduction}

With the rapid development of urbanisation and the economy, high-rise structures play an important role in urban modernisation. High-rise structures provide convenience to the society but also bring new challenges in engineering. With the continuous innovation of construction technologies and building materials, high-rise structures have become lighter and more flexible and required less damping; moreover, the structures mainly experience lowfrequency vibrations. Owing to the characteristics of highrise structures, such as a long natural vibration period, multiorder modes participating in vibration, sensitivity to wind, and earthquake-induced responses [1-4], seismic design has always been the focus. Therefore, researchers have conducted a series of studies on improving the seismic performance of high-rise structures, focusing on the application of steel-concrete composite structures and the introduction of energy dissipation measures.

Steel-reinforced concrete (SRC) and concrete-filled steel tubes (CFSTs) have been widely used in high-rise structures in recent years. The core tube of the Shanghai Centre Tower adopted the SRC structure, and through a shaking table test of a 1/40-scale model, Tian et al. [5] showed that the structure could meet the seismic performance target required by the design. Cao [6,7] took Beijing China Zun as a prototype and, through a series of seismic performance tests, found that the CFST mega-column (with a complex cross section and multiple cavities) could significantly improve the bearing capacity and elastic deformation capacity of the structure. Guangzhou's New TV Tower [8] and Tianjin's Jin Tower [9] adopted CFST mega-columns as the main bearing members. Through theoretical analysis and experimental research, it was concluded that these structures had a good 
deformation capacity and good ductility, along with a certain seismic reserve capacity. Nie et al. [10], Wang et al. [11], Uy et al. [12], and other scholars also conducted a series of studies on the bearing capacity and seismic performance of steel-concrete composite structures and demonstrated their effectiveness in applications for high-rise structures. At present, studies worldwide have shown that SRC and CFSTs can evidently improve the seismic performance of a structure; nevertheless, with a continuous increase in building height, it also leads to higher requirements for its mechanical performance. The connection performance between the steel and concrete is a key parameter affecting the seismic performance of steel-concrete composite structures, but the quantitative evaluation method for the connection mechanism between them remains imperfect.

Therefore, the introduction of energy dissipation measures in high-rise structures has become a research hotspot. Tang [13] set 30 viscous dampers in the sightseeing tower of the Nanjing Olympic Sports Centre for wind-induced vibration control. The dynamic responses of the structure decreased, and the comfort requirements for the sightseeing platform were met. Venanzi [14] effectively reduced the dynamic responses of a high-rise structure under a wind load by setting an optimised tuned mass damper (TMD). Fan et al. [15] used a high-level fire water tank as a mass block and combined it with viscous dampers to form a TMD system for effectively suppressing the resonance responses of the Beijing Olympic Tower caused by dense crowd excitations. Armali et al. [16] studied the vibration control of a 40story building with friction dampers and optimised the number and location of the dampers. The results showed that the friction dampers can significantly reduce the dynamic response of the structure under seismic load and verified the effectiveness of friction dampers in high-rise structures. Liang [17] studied the seismic control of a highrise structure with a metal damper. The results showed that the metal damper had good seismic performance and achieved the expected seismic control effect. Qian and Ding [18] took the Beijing CCTV Tower as a prototype and analysed the influence of an annular tuned liquid damper (TLD) on the tower through a shaking table test of a $1 / 150$ scale model. The results indicated that the TLD could effectively decrease the resonance response of the first mode of the structure. Both the Zhuhai Jinshan Building [19] and Dalian International Trade Building [20] set a rectangular TLD water tank on top of their main structure; this evidently reduced the acceleration response of the top and improved the comfort in the building under a wind load. Naeim et al. [21] introduced a high-rise structure with particle dampers in the centre of Santiago, which suffered from the 2010 Chilean earthquake. To some extent, the study indicated that particle dampers can be applied on high-rise structures. Lu et al. [22] applied tuned particle damper technology for the wind-induced vibration control of high-rise structures and indicated that the tuned particle damper could be used to decrease the wind-induced vibration response of the top of a high-rise structure. Wang [23-25] introduced an adaptive TMD which can retune its frequency and damping ratio in real time based on the vibration state of the structure. The adaptive TMD was applied to a wind-sensitive concrete chimney. And, the results showed that the adaptive TMD had better control effect and robustness than that of passive TMD. Wang et al. [26] introduced a Tuned Liquid Column Damper-Inerter (TLCDI) system to control the seismic response of adjacent high-rise buildings. The results indicated that the optimum TLCDI system can significantly reduce the peak acceleration of both adjacent high-rise buildings. The recent findings show that different types of dampers have achieved some beneficial performance in the seismic control of high-rise structures. Energy dissipation measures can reduce the seismic response, wind-induced response, and human-induced vibration of high-rise structures to a certain extent. However, owing to the multiorder modes participating in the vibration of high-rise structures, all of the above dampers have certain limitations in seismic control. A single TMD or TLD can only reduce the vibration of a low order (or one certain order) of the controlled structure, and their robustness is poor. The soft steel members in the metal dampers may yield when the deformation is large. In addition, as compared to a singlestory building, with the high stiffness of the high-rise structure, the ability to improve the stiffness of the metal damper is limited and the local energy dissipation is not evident. The friction damper may produce a permanent displacement after an earthquake, thereby requiring maintenance and protection in the later stage; moreover, the permanent displacement will greatly weaken the damping performance of the damper. The damping effect of viscous dampers is closely related to the displacement and velocity of the controlled structure, and the energy dissipation and damping capacity are limited for long-period and low-frequency high-rise structures. The particle dampers have good robustness and good control effects on the multiorder modes of structures, but their damping effects are poor before the damping particles start to vibrate. The adaptive TMD can avoid the disadvantage of poor robustness of traditional passive TMD, and the TLCDI system can provide a certain damping effect on both adjacent buildings. However, the design and practical operability of the adaptive TMDs and the TLCDI systems are more complex than those of passive TMDs. The adaptive method and simply application method of the adaptive TMDs and the TLCDI systems are still a hotspot study.

In recent years, the theory and technologies for multiple TMDs (MTMDs) have been developed rapidly [27-30]. Compared with TMD, a MTMD has a wider damping frequency band, has better robustness, and provides a certain damping effect under microvibration. Li [31], Bandivadekar and Jangid [32], and Tharwat [33] et al. had studied applications of MTMDs in engineering, and the results showed that the MTMD has superior application prospects for structural seismic control. Moreover, Wang et al. [34] introduced an adaptive-passive variable mass multiple TMD (APVM-MTMD) system, and a large-span floor structure was proposed as a case study. The results indicated that the damper system could retune itself and had better vibration control effect. De [35] studied a multiTMDI (MTMDI) system and applied it on the vibration 
control of adjacent high-rise buildings. The MTMDI system was arranged between the adjacent buildings. The relative acceleration response of the adjacent structures can introduce a large reaction force on the inserter device in MTMDI. And, the reaction force of the MTMDI can decrease the dynamic response of adjacent buildings. The optimised MTMDI provided a better acceleration damping control for adjacent high-rise buildings than a traditional MTMD or a single TMDI. However, owing to the complex structure of the MTMD and the MTMDI systems, the application method for the MTMD and MTMDI need to be further studied. As a special case of MTMD, a double-layer TMD (DTMD) is not only simple in structure but also has mature theoretical analysis. In addition, DTMD also has an evident damping control ability and a better robustness for structural seismic control [36-38]. However, the application method and damping effect of DTMD for practically structures were still unclear, especially for high-rise structures under the ground motions with long-period characteristics.

Herein, through the establishment of a DTMD-singledegree of freedom (SDOF) system and parameter optimisation theory, a DTMD with optimised parameters was designed and manufactured. Then, the DTMD was set in a scale model of a high-rise structure. Different types of ground motions were selected as excitation inputs, such as Site-II ground motions, long-period (LP) ground motions without pulses, and near-fault pulse-type (NFPT) ground motions with different velocity periods. And, a series of shaking table tests were conducted to analyse the damping effect of the DTMD for high-rise structure.

\section{Experimental Program}

2.1. Description of the Scaled Model. The experimental prototype is the Liuan Tower in China, with a height of $308 \mathrm{~m}$ and a weight of $133588 \mathrm{kN}$. The material of the main structure is Q345 steel (yielding stress was $345 \mathrm{MPa}$ ). According to the full-scale finite element model of the structure (excluding the mast), the natural frequencies of the first three order translational formations were obtained, as shown in Table 1.

Considering the bearing capacity of the shaking tables in the Beijing University of Technology, the dimension scale of the model was set to $1 / 20$. The model tower was welded with a steel plate counterweight along the height direction to make its equivalent mass density reach 2.0. The height of the model was $11 \mathrm{~m}$ without the mast. And, the weight of the model was $32.2 \mathrm{kN}$ with the counterweight. The scaled model was made of the same material as the prototype. The other physical quantities were strictly simulated based on the similarity relationships [39] shown in Table 2. Because the weight and height of the model was high and the test model was axisymmetric, the excitations were only input along the $X$-direction. The acceleration, displacement, and strain sensors were used to monitor the dynamic response of the model. The layout of measuring points is shown in Figure 1(a), and the designed test model is shown in Figure 1(b).
TABLE 1: Natural vibration parameters.

\begin{tabular}{lcc}
\hline Frequency & Value $(\mathrm{Hz})$ & Vibration mass \\
\hline$\omega_{1}$ & 0.132 & 67 \\
$\omega_{2}$ & 0.719 & 76 \\
$\omega_{3}$ & 1.340 & 86 \\
\hline
\end{tabular}

2.2. Dynamic Characteristics of the Model. Table 3 gives the natural frequencies of the model tower obtained by inputting white noise signal, as well as the frequencies of the finite element analysis (FEA) results and the theoretical analysis results. To obtain the frequencies of the FEA and the theoretical analysis results, firstly, the prototype finite element model (FEM) was constructed based on the Midas Gen V2019 platform. Then, the frequencies of the prototype FEM were analysed (shown in Table 1). Secondly, the theoretical frequencies of the scaled model can be obtained through multiplying the frequencies of the prototype FEM by the similarity coefficient (shown in Table 2). However, the FEA frequencies of the scaled model can be directly obtained through the analysis results of the scaled FEM based on the Midas Gen V2019 platform.

According to the data in Table 3, the deviation of the first-order frequency obtained from the scaled FEA and similarity theory is within $8 \%$ and the deviations of the second-order and third-order frequencies are less than $5 \%$. Moreover, the deviations between the frequency of the scaled test model and the data of the scaled FAM are also within $10 \%$. Considering the setting error of the additional mass and the manufacturing error of the scaled model, both the scaled test model and scaled FEA model can reflect the actual stress and deformation state of the prototype [2].

\subsection{Test Conditions. Liuan Tower was located in a Class-II} site (Site-II), with a 7-degree fortification zone. And, the designed earthquake group was the first group. In this case, the designed seismic response spectrum of the model tower was firstly determined according to the code for seismic design of buildings (GB 50011-2010), and the typical period range of the design response spectrum was also determined as $4 \mathrm{~s} \sim 9 \mathrm{~s}$ based on the basic vibration period of the prototype tower. Then, three Site-II ground motions were chosen from the database of the PEER. Moreover, in order to study the dynamic response law of the SHR structures under the NFPT and LP ground motions, three NFPT ground motions and three LP ground motions without pulses with the same site conditions were also chosen. The response spectrum curves of the ground motions are shown in Figure 2.

As Figure 2 shows, the selected NFPT and the LP ground motions all have the characteristic of long-period effect. The spectrum value of the NFPT and LP ground motions is relatively large in the long-period range $(4 \mathrm{~s} \sim 9 \mathrm{~s})$, which can easily induce larger dynamic response of the prototype structure (the first-order vibration period is about $7.5 \mathrm{~s}$ ). Compared with the NFPT and LP ground motions, the spectrum value of the selected Site-II ground motions is relatively small in the long-period range $(4 s \sim 9 s)$. Detailed 
TABLE 2: Similarity relationships.

\begin{tabular}{lccc}
\hline Physical quantity & Unit & Similarity relationship & Similar coefficient \\
\hline Scale & $(\mathrm{L})$ & $S_{L}$ & $1 / 20$ \\
Displacement & $(\mathrm{L})$ & $S_{\delta}=S_{L}$ & $1 / 20$ \\
Elastic modulus & $\left(\mathrm{FL}^{-2}\right)$ & $S_{E}$ & 1 \\
Equivalent mass density & $\left(\mathrm{FL}^{-4} \mathrm{~T}^{2}\right)$ & $S_{\rho_{e}}$ & 2 \\
Strain & - & $S_{\varepsilon}$ & 1 \\
Stress & - & $S_{\sigma}=S_{E} S_{\varepsilon}$ & 1 \\
Frequency & $\left(\mathrm{T}^{-1}\right)$ & $S_{\omega}=1 / S_{T}$ & 14.142 \\
Acceleration & $\left(\mathrm{LT}^{-2}\right)$ & $S_{a}=S_{E} /\left(S_{L} S_{\rho_{e}}\right.$ & 10 \\
\hline
\end{tabular}
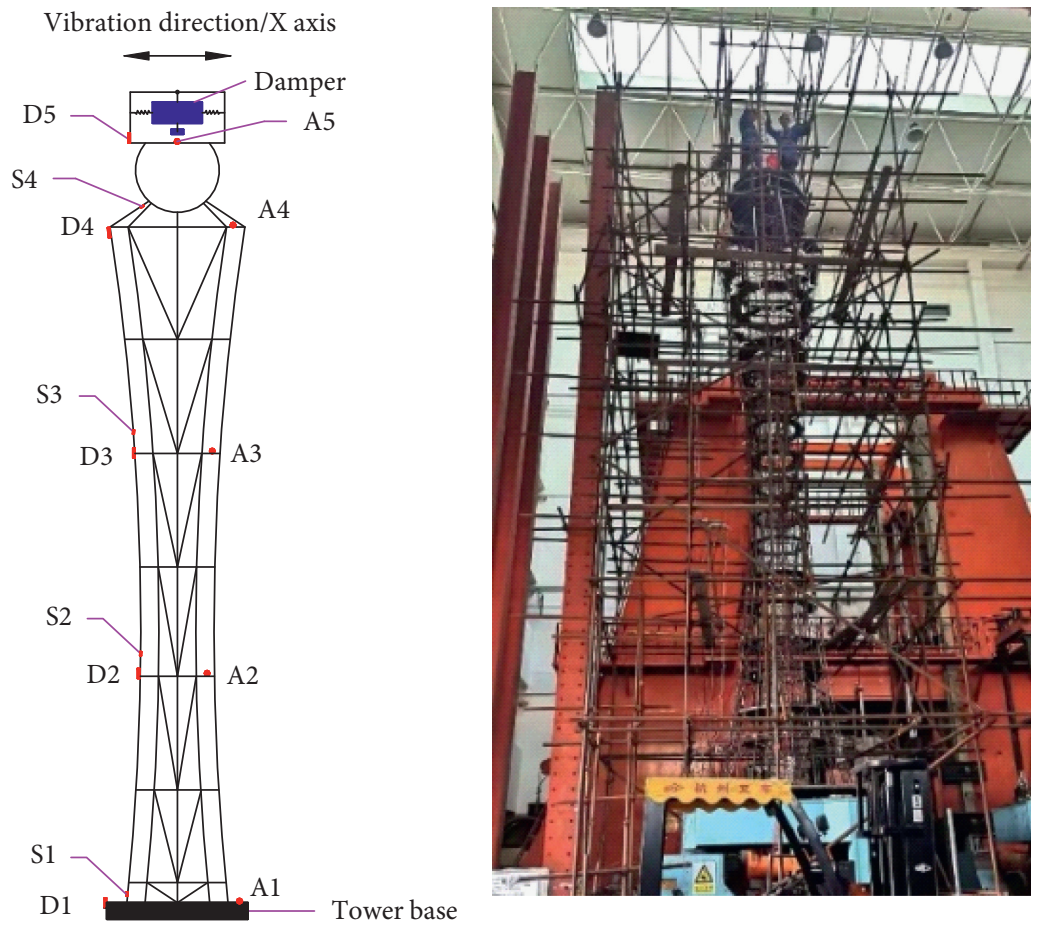

A - Acceleration

D - Displacement

$S$ - Strain

(a)

(b)

FIgURE 1: Model tower and its measuring points. (a) Layout of measuring points. (b) Test model.

TABLE 3: Comparison of the dynamic characteristics of the model.

\begin{tabular}{lccccc}
\hline Frequency & FEA value $(\mathrm{Hz})$ & Theory value $(\mathrm{Hz})$ & Test value $(\mathrm{Hz})$ & \multicolumn{2}{c}{$\begin{array}{c}\text { Deviation rate }(\%) \\
\text { (FEA-theory)/theory }\end{array}$} \\
\hline$\omega_{1}$ & 1.730 & 1.870 & 1.640 & 7.50 & 5.20 \\
$\omega_{2}$ & 9.810 & 10.170 & 9.200 & 3.50 & 6.20 \\
$\omega_{3}$ & 18.030 & 18.950 & 16.490 & 4.90 & 8.50 \\
\hline
\end{tabular}

information on each ground motion is shown in Table 4. Notably, the three NFPT ground motions had different velocity pulse periods (VPPs). However, the VPP of $7.50 \mathrm{~s}$ was basically the same with the natural vibration period of the original structure $(7.58 \mathrm{~s})$. Moreover, it can also be seen that the bracketed and energy duration of the LPs are much longer than that of the NFPTs and Site-II motions. Accordingly, with the same PGA, the dynamic response of the controlled structure under the LPs will supposedly be larger than that of under the NFPTs and Site-II motions.

Because the seismic fortification intensity was $7^{\circ}$, the peak accelerations corresponding to the frequent earthquake E1 and fortification earthquake E2 were $0.035 \mathrm{~g}$ and $0.1 \mathrm{~g}$, respectively. Considering the safety of the test process and effectiveness of the damper, only the above two acceleration peaks were considered. According to Table 2, the peak 


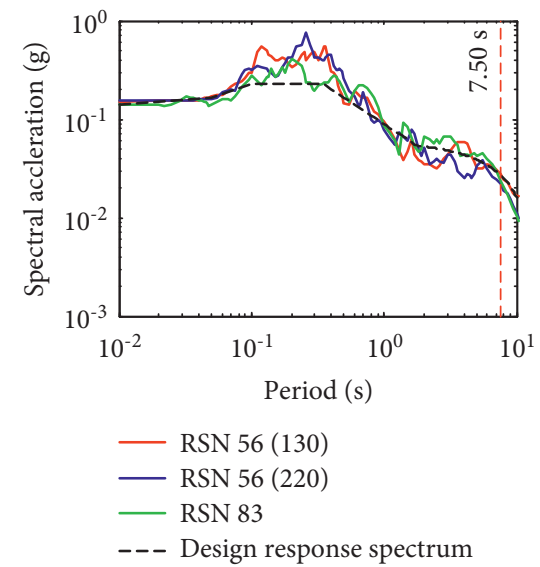

(a)

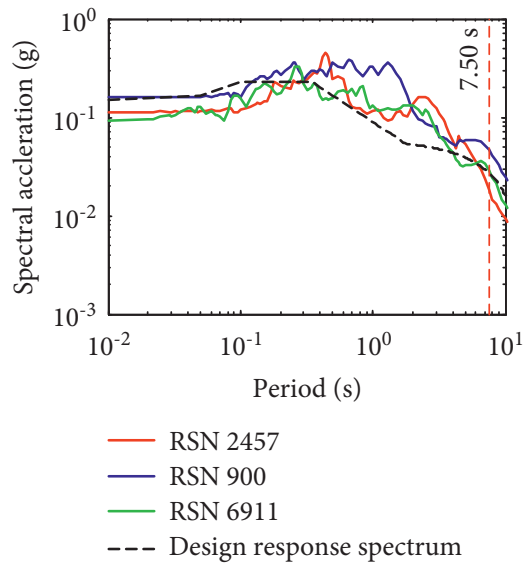

(b)

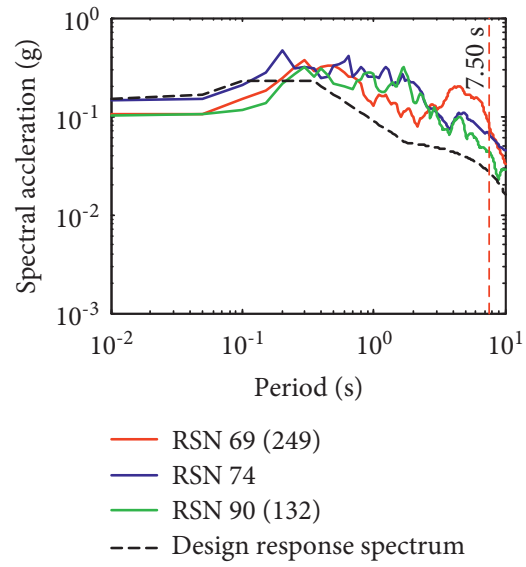

(c)

FIgURE 2: Acceleration response spectra of selected ground motions compared with the design response spectrum. (a)Site-II ground motions. (b) NFPT ground motions. (c) LP ground motions.

TABLE 4: Information of the ground motions.

\begin{tabular}{|c|c|c|c|c|c|c|c|}
\hline Excitation types & $\begin{array}{l}\text { Record sequence } \\
\text { number (RSN) }\end{array}$ & Name & $\begin{array}{l}\text { VPP } \\
(\mathrm{s})\end{array}$ & M & $\begin{array}{l}\text { Bracketed duration } \\
\qquad\left(\geq 1 / 3 A_{\max }\right) \text { (s) }\end{array}$ & $\begin{array}{l}\text { Energy duration } \\
(5 \%-95 \%)(\mathrm{s})\end{array}$ & $\begin{array}{c}\text { Peak ground } \\
\text { acceleration (PGA) } \\
(g)\end{array}$ \\
\hline \multirow{3}{*}{ Site-II } & $56(130)$ & San Fernando & - & 6.61 & 11.6 & 18.9 & 0.071 \\
\hline & $56(220)$ & San Fernando & - & 6.61 & 14.7 & 18.9 & 0.071 \\
\hline & 83 & San Fernando & - & 6.61 & 8.4 & 14.3 & 0.074 \\
\hline \multirow{3}{*}{$\begin{array}{l}\text { Near-fault pulse- } \\
\text { type (NFPT) }\end{array}$} & 2457 & $\begin{array}{l}\text { Chi-Chi_ } \\
\text { Taiwan-03 }\end{array}$ & 3.18 & 6.20 & 5.7 & 12.9 & 0.187 \\
\hline & 900 & Landers & 7.50 & 7.28 & 8.3 & 18.9 & 0.245 \\
\hline & 6911 & $\begin{array}{c}\text { Darfield_New } \\
\text { Zealand }\end{array}$ & 9.92 & 7.00 & 7.6 & 9.5 & 0.450 \\
\hline \multirow{3}{*}{ Long period (LP) } & 69 (249) & San Fernando & - & 6.61 & 51.7 & 52.4 & 0.029 \\
\hline & 74 & San Fernando & - & 6.61 & 33.6 & 29.6 & 0.007 \\
\hline & $90(132)$ & San Fernando & - & 6.61 & 51.4 & 49.3 & 0.017 \\
\hline
\end{tabular}

accelerations of E1 and E2 were adjusted to $0.35 \mathrm{~g}$ and $1.0 \mathrm{~g}$, respectively. The ground motions were input along the horizontal direction ( $X$-direction), which was the same as the vibration direction of the damper.

\section{Design of the Damping Scheme}

\subsection{Optimisation Method of Damper Parameters}

3.1.1. Mechanical Model of Double-Layer Tuned Mass Damper (DTMD). As shown in Figure 3(a), the DTMD comprises an upper TMD and lower TMD in series and the upper TMD is connected to the controlled structure. The work of the DTMD is as follows: the upper tuned mass can swing around the controlled structure through the universal hinge $\mathrm{C}$ (it can be adjusted as a one-direction hinge when the vibration is unidirectional, the same as below) and connecting rod $\mathrm{D}$. The lower tuned mass can swing around the upper tuned mass through the universal hinge $\mathrm{E}$ and connecting rod $\mathrm{F}$.

According to the Code for Seismic Design of Buildings, when the mode decomposition response spectrum method is adopted, the horizontal seismic effect can only take the first
2-3 modes for structures without using a torsional coupling calculation. The number of modes can be appropriately increased when the natural vibration period is greater than $1.5 \mathrm{~s}$ or when the height-width ratio of the buildings is greater than 5. By neglecting the coupling effect of every translational formation of the high-rise structure and taking the first $n$-order translational DOFs as an example, the $i$ order translational formation can be regarded as a SDOF structure with the same vibration participation mass and same frequency as the $i$-order formation. We assumed that the mass, the stiffness, and the damping coefficient of a SDOF structure were $m_{0}, k_{0}$, and $c_{0}$, respectively. The upper tuned mass had a mass of $m_{1}$ and was connected to the controlled structure, and its stiffness $k_{1}$ and damping coefficient $c_{1}$ were provided by the universal hinge $\mathrm{C}$ and connecting rod $\mathrm{D}$. The mass of the lower tuned mass was $m_{2}$, and its stiffness $k_{2}$ and damping coefficient $c_{2}$ were provided by the universal hinge $\mathrm{E}$ and connecting rod $\mathrm{F}$. The external harmonic excitation was $F=P_{0} \exp (i \omega t)(i=\sqrt{-1})$. The relative displacement response between the controlled structure and the ground was $x_{0}(t)$, and the corresponding displacement response of the upper and lower tuned masses was $x_{1}(t)$ and $x_{2}(t)$, respectively. According to the DTMD 


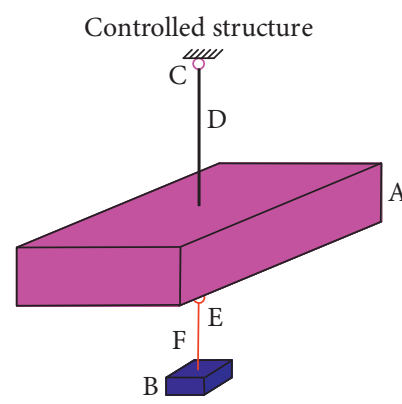

(a)

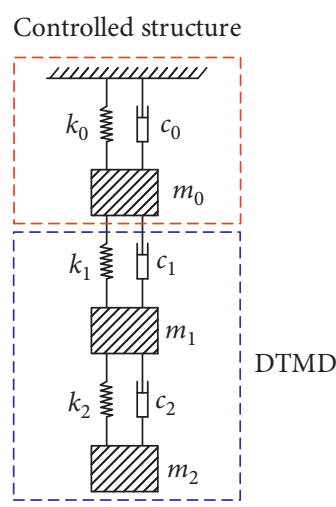

(b)

FIgURe 3: Double-layer tuned mass damper (DTMD) model. (a) Model sketch. (b) Mechanical model.

mechanical model in Figure 3(b), equation (1) could be obtained $[36,38,40,41]$ as follows:

$$
M \ddot{X}+C \dot{X}+K X=F
$$

where $\mathbf{M}=\left[\begin{array}{ccc}m_{0} & 0 & 0 \\ 0 & m_{1} & 0 \\ 0 & 0 & m_{2}\end{array}\right], \quad \mathbf{C}=\left[\begin{array}{ccc}c_{0}+c_{1} & -c_{1} & 0 \\ -c_{1} & c_{1}+c_{2} & -c_{2} \\ 0 & -c_{2} & c_{2}\end{array}\right]$, $\mathbf{K}=\left[\begin{array}{ccc}k_{0}+k_{1} & -k_{1} & 0 \\ -k_{1} & k_{1}+k_{2} & -k_{2} \\ 0 & -k_{2} & k_{2}\end{array}\right], \quad \mathbf{X}=\left\{\begin{array}{c}x_{0}(t) \\ x_{1}(t) \\ x_{2}(t)\end{array}\right\}$, and $\mathbf{F}=$ $\left\{\begin{array}{c}P_{0} \exp (i \omega t) \\ 0 \\ 0\end{array}\right\}$

If $x_{j}(t)=h_{j}(\omega) \exp (i \omega t)(j=0,1,2)$, then a calculation can be made as follows:

$$
\left(-\omega^{2} M+i \omega C+K\right) h(\omega)=F_{0} .
$$

Here, the variables are determined as follows: $h(\omega)=$ $\left\{\begin{array}{l}h_{0}(\omega) \\ h_{1}(\omega) \\ h_{2}(\omega)\end{array}\right\}$ and $F_{0}=\left\{\begin{array}{c}P_{0} \\ 0 \\ 0\end{array}\right\} ;$ let $\mu_{1}=\left(m_{1} / m_{0}\right), \mu_{2}=\left(m_{2} /\right.$ $\left.m_{0}\right), \lambda_{1}^{2}=\left(\omega_{1}^{2} / \omega_{0}^{2}\right), \lambda_{2}^{2}=\left(\omega_{2}^{2} / \omega_{0}^{2}\right), \xi_{j}=\left(c_{j} / 2 m_{j} \omega_{j}\right), \lambda^{2}=\left(\omega^{2}\right.$ $\left./ \omega_{0}^{2}\right)$, and $\Delta_{s t}=\left(P_{0} / k_{0}\right)$.

Equation (2) can be expressed as follows:

$$
\left(-\mathbf{A}_{1}+\mathbf{A}_{2}+\mathbf{A}_{3}\right) h(\omega)=\Delta .
$$

Here, the variables are determined as follows:

$$
\begin{aligned}
& \mathbf{A}_{1}=\left[\begin{array}{ccc}
\lambda^{2} & 0 & 0 \\
0 & \mu_{1} \lambda^{2} & 0 \\
0 & 0 & \mu_{2} \lambda^{2}
\end{array}\right], \\
& \mathbf{A}_{2}=2 \lambda i\left[\begin{array}{ccc}
\xi_{0}+\xi_{1} \mu_{1} \lambda_{1} & -\xi_{1} \mu_{1} \lambda_{1} & 0 \\
-\xi_{1} \mu_{1} \lambda_{1} & \xi_{1} \mu_{1} \lambda_{1}+\xi_{2} \mu_{2} \lambda_{2} & -\xi_{2} \mu_{2} \lambda_{2} \\
0 & -\xi_{2} \mu_{2} \lambda_{2} & \xi_{2} \mu_{2} \lambda_{2}
\end{array}\right], \\
& \mathbf{A}_{3}=\left[\begin{array}{ccc}
1+\mu_{1} \lambda_{1}^{2} & -\mu_{1} \lambda_{1}^{2} & 0 \\
-\mu_{1} \lambda_{1}^{2} & \mu_{1} \lambda_{1}^{2}+\mu_{2} \lambda_{2}^{2} & -\mu_{2} \lambda_{2}^{2} \\
0 & -\mu_{2} \lambda_{2}^{2} & \mu_{2} \lambda_{2}^{2}
\end{array}\right], \text { and } \Delta=\left(\begin{array}{c}
\Delta_{s t} \\
0 \\
0
\end{array}\right) .
\end{aligned}
$$

In this study, we let $s_{j}=2 \xi_{j} \mu_{j} \lambda_{j} \lambda i+\mu_{j} \lambda_{j}^{2} \quad(j=0,1,2)$ and $\mu_{0}=1$ and $\lambda_{0}=1$. Then, the displacement dynamic magnification factor (DDMF) of the controlled structure can be obtained as follows:

$$
\mathrm{DDMF}=\frac{-\mu_{1} \mu_{2} \lambda^{4}+I_{0}(\mu, s) \lambda^{2}-s_{1} s_{2}}{\mu_{1} \mu_{2} \lambda^{6}-I_{1}(\mu, s) \lambda^{4}+I_{2}(\mu, s) \lambda^{2}-s_{0} s_{1} s_{2}}
$$

The values of the variables are calculated as follows:

$$
\begin{aligned}
& I_{0}(\mu, s)=s_{2} \mu_{1}+s_{1} \mu_{2}+s_{2} \mu_{2}, \\
& I_{1}(\mu, s)=\mu_{1} s_{2}+\mu_{2} s_{1}+\mu_{2} s_{2}+s_{0} \mu_{1} \mu_{2}+s_{1} \mu_{1} \mu_{2}, \\
& I_{2}(\mu, s)=s_{1} s_{2}+s_{0} s_{2} \mu_{1}+s_{0} s_{1} \mu_{2}+s_{1} s_{2} \mu_{1}+s_{0} s_{2} \mu_{2}+s_{1} s_{2} \mu_{2} .
\end{aligned}
$$

3.1.2. Parameter Optimisation Method. Based on the MTMD parameter optimisation method, the DTMD was optimised using a numerical optimisation method $[38,42-46]$. Then, two important evaluation parameters of the SDOF structure with $n$-order TMDs can be given as follows:

$$
\begin{aligned}
& \mathbf{P}_{1}=\sum_{i=1}^{n+1} \frac{P_{\max }(i)}{n+1}, \\
& \mathbf{P}_{2}=\sum_{j=1}^{n+1}\left\{\sum_{i=1}^{n+1} \frac{P_{\max }(i)}{n+1}-P_{\max }(j)\right\}^{2} .
\end{aligned}
$$

Here, $P_{\max (i)}$ denotes the peaks of the displacement response curve, $P_{1}$ denotes the average value of the peaks, and $P_{2}$ denotes the deviation value of the peaks. Shen [47] introduced an optimised method for a double-layer tuned particle damper. However, that method did not consider the effect of multimode participation. According to Table 1, the cumulative vibration mass participation factor for the first three modes of the prototype reaches $86 \%$. Accordingly, the optimisation method of DTMD for HRS must consider the effect of multimode participation. Then, according to equations (6) and (7), the optimisation parameter expression of the DTMD is as follows: 


$$
\mathrm{Z}\left(\mu, \mu_{1}, \mu_{2}, \xi_{0}, \xi_{1}, \xi_{2}, \lambda_{1}, \lambda_{2}, \lambda\right)=\min \left[\phi_{1}\left(P_{11}+P_{12}\right)+\phi_{2}\left(P_{21}+P_{22}\right)+\phi_{3}\left(P_{31}+P_{32}\right)\right]
$$

Here, $P_{i 1}$ and $P_{i 2}$ represent the optimisation indexes 1 and 2 of the displacement response peak of the $i$-order mode, respectively. $\phi_{i}$ represents the ratio of the vibration mass participation factor of the $i$-order mode to the total vibration mass participation factor for the first $\mathrm{N}$-order modes. In this study, $i=1,2,3$ and $N=3$, and the corresponding values of $\phi_{1}, \phi_{2}$, and $\phi_{3}$ are $0.779,0.105$, and 0.116 , respectively. Because the additional mass of the damper has a significant influence on the stress state of the controlled structure $[14,15,18-22]$ and that the damping effect will be poor when the additional mass ratio is excessively small, the additional mass ratio of the tuned damper is mostly controlled to be in the range of $2 \%-5 \%$. In this study, the additional mass ratio $\mu$ of the optimised DTMD was 5\%. The test model was a steel structure, and the damping ratio $\xi_{0}$ of the controlled structure was set at 0.02 , according to the measured value. It should be pointed out that the controlled structure was assumed to be in an elastic state and the damping variation of the controlled structure (including the soil damping and structure damping) was not considered. $\xi_{1}$ and $\xi_{2}$ were the damping ratios of the upper and lower tuned masses, respectively, and their values were in the range of $0-0.15$ and $0-0.4$. $\lambda_{1}$ and $\lambda_{2}$ represented the ratios of the natural frequencies of the upper and lower tuned masses to the controlled structure, respectively. And, their values were all in the range of 0.6 to 1.4. $\lambda$ was the ratio of natural frequency of the controlled structure to the excitation and was within the range of 0.60 to 1.40 . Moreover, there may be some local minimum and saddle point of the optimisation results. To avoid the local minimum and saddle point, we usually draw all the displacement responses of the controlled system with different optimisation results and select a best one as the optimisation parameters. Figure 4(a) shows a comparison of the optimisation results for TMD, MTMD, and DTMD. The theoretical optimisation results of the DTMD-SDOF system are shown in Figure 4(b).

As shown in Figure 4(a), the damping frequency band of the optimised TMD is about $0.16 \lambda_{0}$, while the damping frequency band of the optimised DTMD is greatly increased to $0.30 \lambda_{0}$ under the same optimisation conditions. The frequency range of the optimised DTMD is wider than that of the TMD. The optimised DTMD has essentially the same damping frequency band as the optimised MTMD. In addition, it can be seen from Figure 4(b) that the damping effect and robustness of the DTMD decrease with an increase in the damping ratio of the upper TMD.

3.2. Damper Design. The experimental validation work is also a data support and methodological reference for the future application of shock absorbers. Transforming theoretical optimisation parameters into practical available parameters has always been hotspot study in engineering field. The application method (including design and manufacture method) of optimisation parameters is also necessary to be verified by experiments. According to the dynamic parameters of the prototype tower and optimisation method described in Section 3.1, the optimised parameters of the DTMD in this study were determined, as shown in Table 5.

According to Table 5, the mass of the upper TMD can be determined as $\mathrm{m}_{1}=0.0462 \mathrm{~m}_{0}$ and the natural frequency is $f_{1}=f_{0}=1.64 \mathrm{~Hz}$, in which $m_{0}$ is the first-mode participation mass of the prototype model. Also, the maximum angular displacement of the upper TMD without damping was always less than $\pi / 18$ (10 degrees) in this study. The influence of the angular displacement can be ignored. Then, the connection stiffness between the upper TMD and controlled model can be simplified as equation (9).

$$
\omega_{1}=\sqrt{\frac{g}{L}+\frac{k_{1}}{m_{1}}\left(\frac{h}{L}\right)}
$$

Here, $\omega_{1}$ is equal to $10.24 \mathrm{rad} / \mathrm{s}$ and it represents the natural frequency of the upper TMD without damping. The acceleration of gravity is $g=9.8 \mathrm{~m} / \mathrm{s}^{2} . L$ is the effective pendulum length and was $370 \mathrm{~mm}$ in this test. $h$ represents the distance between the upper connection point and the lower connection point and in this study, it was the same as the effective pendulum length $L$. The external spring stiffness was obtained through equation (9) and was equal to $7780 \mathrm{~N} /$ $\mathrm{m}$. The stiffness of the outer spring was obtained by customising the tension spring and met the deformation requirement of the pulling length.

The mass and natural frequency of the lower TMD are $m_{2}=0.0038 m_{0}$ and $f_{2}=0.91 f_{0}=1.49 \mathrm{~Hz}$, respectively. Because the mass of the lower TMD was relatively small, its natural frequency was determined by the pendulum length. Then, the pendulum length of the lower TMD was obtained through $\omega_{2}=\sqrt{g / L}$ and was equal to $111 \mathrm{~mm}$. Based on the optimised parameters in Table 5, the equivalent damping ratio of the lower TMD was approximated by

$$
\xi_{2}=\frac{C_{2}}{2 m_{2} \omega_{2}}
$$

Here, $C_{2}$ is the equivalent damping coefficient and can be calculated from the required equivalent damping ratio. In this study, the equivalent damping at the unidirectional hinge was provided by its friction. According to the principle of energy equivalence, if the areas of the friction-displacement curve and equivalent viscous damping-displacement curve are the same under the same harmonic excitation, then they are equivalent. The friction coefficient $\mu$ between the unidirectional hinge of the upper TMD and lower TMD was obtained based on their area equivalence.

$$
\mu=\frac{\pi C_{2}\left(\omega_{2} s\right)}{4 m_{2} g} .
$$

In this study, the DTMD mainly concerned the firstorder vibration mode and the displacement response amplitude $s$ in equation (11) was determined according to the displacement response amplitude of the DTMD. Because the 


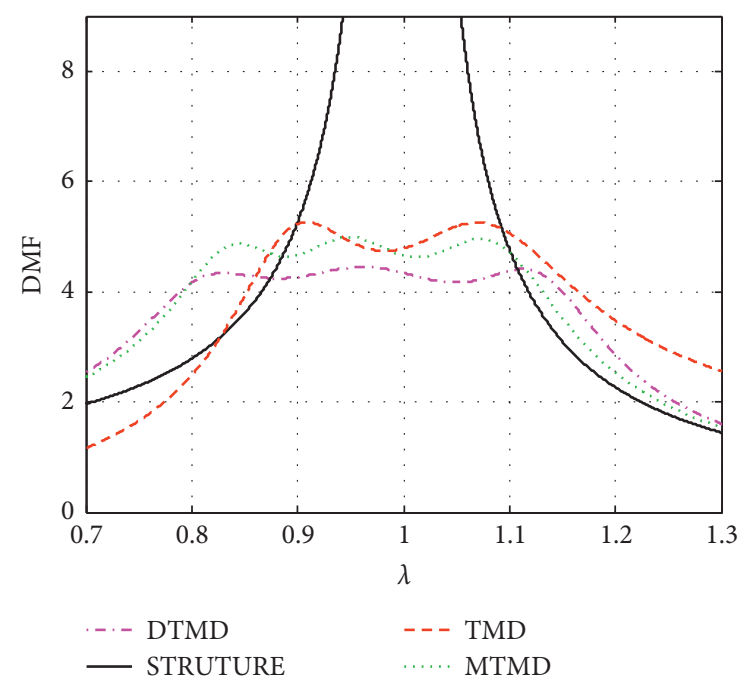

(a)

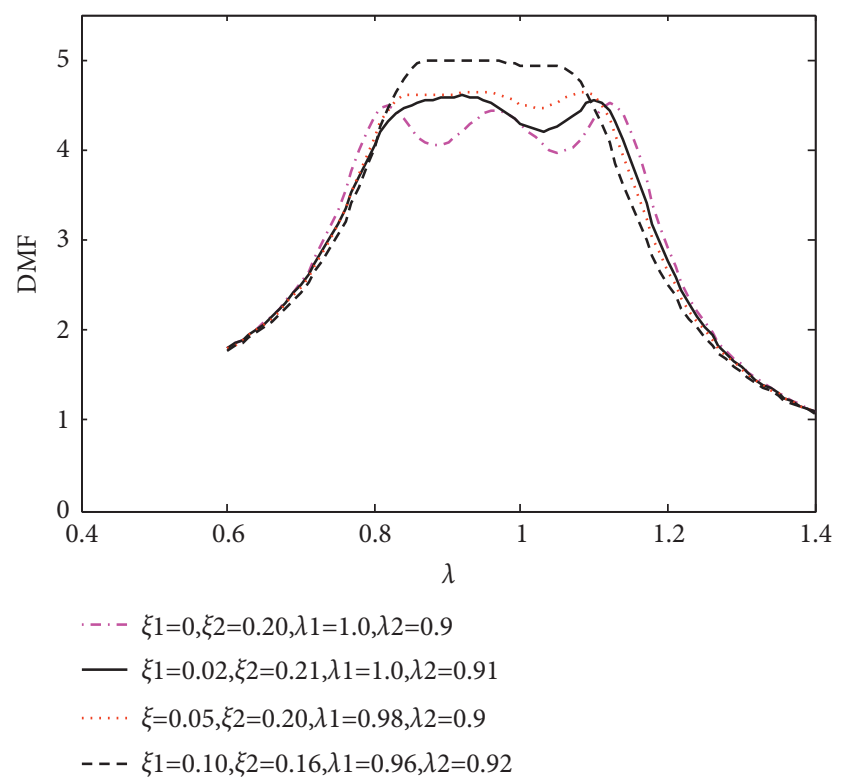

(b)

FIgURE 4: Typical optimisation results of the damper $\left(\mu=0.05 ; \xi_{0}=0.02\right)$. (a) Comparison of DTMD, TMD, and multiple TMD (MTMD). (b) Optimised DTMD.

TABle 5: Optimised parameters of the double-layer tuned mass damper (DTMD).

\begin{tabular}{lccc}
\hline Parameter & $\mu$ & $\xi$ & $\lambda$ \\
\hline Upper tuned mass damper & 0.0462 & 0.02 & 1.00 \\
Lower tuned mass damper & 0.0038 & 0.21 & 0.91 \\
\hline
\end{tabular}

first-mode participation mass of the model and the additional mass of the DTMD satisfied $m_{0}=n m$, the first-order stiffness between them satisfied $k_{0}=n k$. The peak displacement $d_{0}$ of the model and the peak displacement $d$ of the DTMD must satisfy an equation, as follows:

$$
\frac{d}{d_{0}}=\frac{1}{2} \pm \sqrt{n+\frac{1}{4}}
$$

Since the parameter $n$ is equal to $20, d_{0}$ was approximately $7.0 \mathrm{~mm}$ under frequent earthquakes E1 and $15.0 \mathrm{~mm}$ under fortification earthquakes E2, respectively. The friction coefficient was equal to 0.10 and 0.22 , respectively. In this study, the friction coefficient was obtained by using a steel unidirectional hinge and applying lubricant.

Considering the top space of the model tower, installation position of the damper, length of the springs, and optimised design parameters in Table 5, the upper TMD was composed of the steel box and counterweight. The counterweight was arranged at the centroid position of the steel box, and the total weight of the upper TMD was $99.24 \mathrm{~kg}$. The designed DTMD is shown in Figure 5.

The numerical optimisation showed that a smaller damping ratio of the connection would lead to a more significant damping effect for the DTMD. To verify the theoretical results, this study also considered different boundary conditions for the connection when studying the damping effect of the DTMD. They were (1) case-I (the connection was filled with the polytrifluorochloroethylene (PCTFE), and the equivalent damping ratio was in the range of 0.26 to 0.56 ); (2) case-II (the connection had no treatment, and the equivalent damping ratio was in the range of 0.12 to 0.25 ); (3) case-III (the connection was lubricated with oil, and the equivalent damping ratio was in the range of 0.04 to 0.08 ).

In addition, the displacement response of the upper TMD and the lower TMD were monitored by the displacement sensors. And, a GoPro camera was also used to record the motion state of the damper in real time, as shown in Figure 5(c).

\section{Experimental Results and Analysis}

To better evaluate the seismic performance and control effect of the DTMD, the absolute displacement response (ADR), root mean square (RMS) of the absolute displacement response (RMS-ADR), acceleration response (AR), and strain response (SR) of the top floor were analysed. For effective and efficient calculations, the lower limits of the ADR, AR, and SR were determined as $0.5 \mathrm{~mm}, 20 \mathrm{~cm} / \mathrm{s}^{2}$, and $1 \mu \varepsilon$, respectively. The expressions for the effective RMS and decreasing ratios of each parameter are as follows:

$$
\begin{aligned}
& \lambda_{d}=\operatorname{sqrt}\left(\sum_{i f}^{n} \frac{x_{i}^{2} \geq x_{0}}{n}\right), \\
& \eta_{j}=\left(\frac{\lambda_{j 0}-\lambda_{j}}{\lambda_{j 0}}\right) \times 100 \% .
\end{aligned}
$$

Here, $x_{i}$ denotes the dynamic response at $i$ moment and $\lambda_{j 0}$ denotes the responses of the model without DTMD for each parameter. $j$ can take the values of $1,2,3$, and 4 and represent $\mathrm{ADR}, \mathrm{RMS}-\mathrm{ADR}, \mathrm{AR}$, and $\mathrm{SR}$, respectively. 


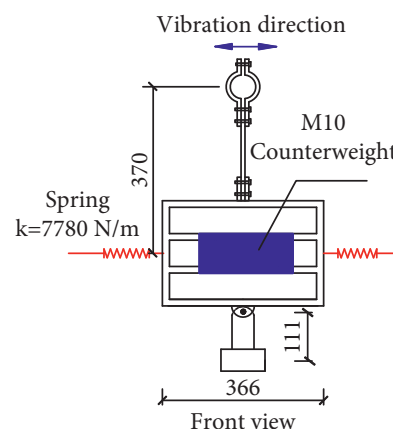

(a)

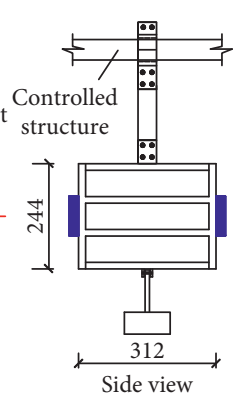

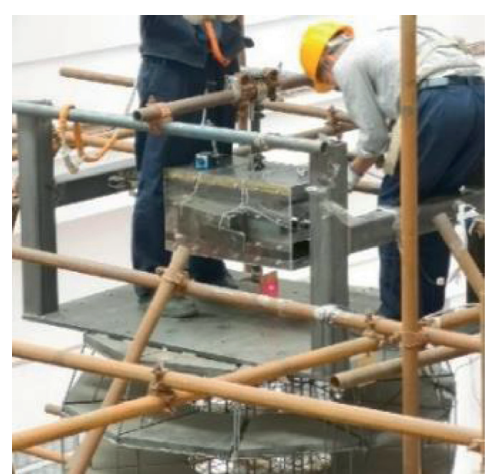

(b)

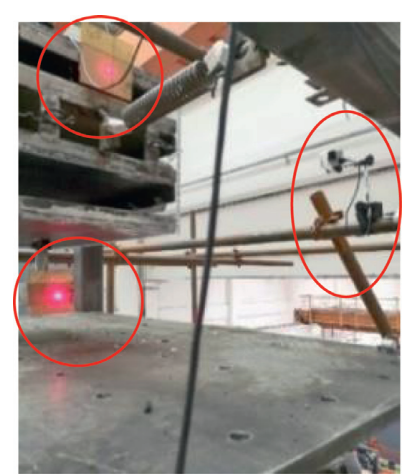

(c)

FIgURE 5: DTMD model and measurement layout. (a) Dimension (mm). (b) DTMD model. (c) Sensors and camera.

4.1. Experimental Results of the Original Model. According to the three types of ground motions selected in Section 2.3, shaking table tests of the original model were firstly carried out. Figure 6 shows the dynamic response curves of the top floor under three typical ground motions.

As shown in Figure 6, the displacement response of the model tower is mainly a low-frequency response under the three typical ground motions, conforming to the response characteristics of high-rise structures. For the E1 and E2 excitations, the ADRs under the NFPT ground motion (RSN900) and the LP ground motion (RSN74) are significantly larger than those under the Site-II ground motion (RSN56 (130)). Moreover, this phenomenon becomes much more evident as the excitation peaks increase. For the E1 and E2 excitations, the amplitudes of ADRs under the RSN74 wave are 1.09 times and 1.89 times larger than those under the RSN56 (130) wave, respectively. Meanwhile, the amplitudes of the ADRs under the RSN900 wave are 1.21 times and 1.85 times larger than those under the RSN56 (130) wave, respectively. In addition, the ADR, RMS-ADR, AR, and SR of the model without the DTMD are given in Table 6.

As shown in Table 6, under the three types of ground motions, the ADR, RMS-ADR, AR, and SR values of the model significantly increase with the increase in amplitude of the excitations. The dynamic response of the model under the NFPT and LP ground motions is more significant than that under the Site-II ground motions. Taking the E2 earthquake as an example, the average peak of the ADRs under Site-II ground motions is $7.87 \mathrm{~mm}$. The corresponding values reach $11.87 \mathrm{~mm}$ and $15.33 \mathrm{~mm}$ under NFPT ground motions and LP ground motions, respectively.

When the velocity pulse period of the NFPT ground motion is close to the natural vibration period of the original model, the dynamic response of the model will be more significant; this is consistent with the research results of Shen et al. [47] and $\mathrm{Xu}$ et al. [48]. Owing to the influence of the long natural vibration period of high-rise structures, the high-frequency component of the ground motions is gradually filtered out in the transmission process and the low-frequency component at the top floor of the structure is greater than that at the bottom floor. Thus, the resonance phenomenon will cause an evident whipcord phenomenon at the top floor of the structure under the LP and NFPT ground motions. For example, under the E2 earthquake, the peaks of the SRs (the S4 measurement point) at the top floor are $378.65 \mu \varepsilon, 1331.92 \mu \varepsilon$, and $1646.60 \mu \varepsilon$ under Site-II ground motion RSN56 (130), NFPT ground motion RSN900, and LP ground motion RSN74, respectively. In contrast, the values (the S1 measuring point) at the bottom floor are $63.24 \mu \varepsilon, 193.72 \mu \varepsilon$, and $239.43 \mu \varepsilon$ under the same cases, respectively.

\subsection{Experimental Results of the Damping Model}

4.2.1. Basic Dynamic Characteristics. Table 7 shows the firstorder frequency of each model with and without the DTMD. It can be seen that the first-order frequency of the scaled model has negligible changes before and after the test. Thus, the model tower is always in the elastic stage during the test, and the analysis data show high reliability. Compared with the original structure, the vibration frequencies of the test model with the DTMD decrease slightly. The connection case of the DTMD has little effect on the dynamic characteristics of the DTMD model system. In addition, owing to the small weight of the lower TMD, the acceleration sensor is only installed on the upper TMD. Under case-III, it can be seen that the first natural vibration frequency of the upper TMD is basically consistent with the design frequency. Accordingly, both the design and processing of the DTMD are effective.

4.2.2. Site-II Ground Motions. Figure 7 gives the ADR and AR of the model before and after the DTMD installation under the RSN56 (130) wave. The connection case of the DTMD was case-III.

As shown in Figure 7, the DTMD can effectively reduce the displacement and acceleration responses at the top of the test model. At the initial stage, both the displacement response and acceleration response curves of the model with and without the DTMD partially overlap and the difference in the dynamic response between them gradually increases in the later stages. This phenomenon shows that the DTMD has the same characteristics as the tuned damper; that is, the damping effect is not evident in the early stage but is evident in the later stages. Table 8 provides 


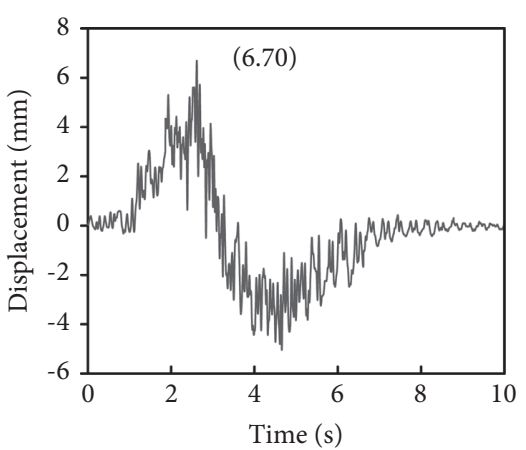

(a)

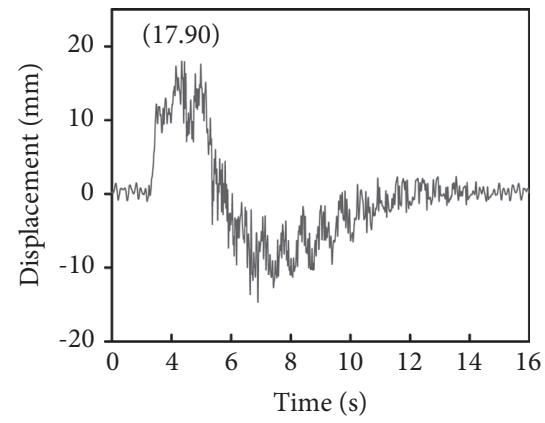

(d)

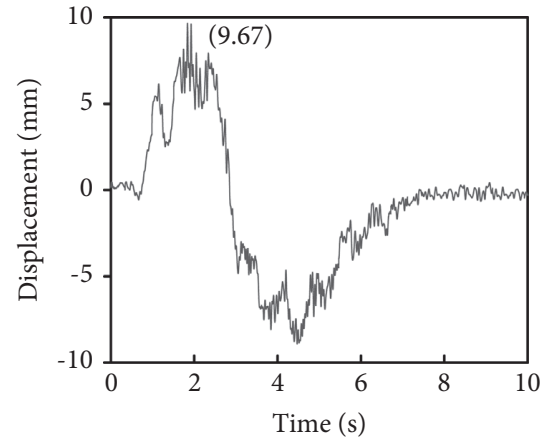

(b)

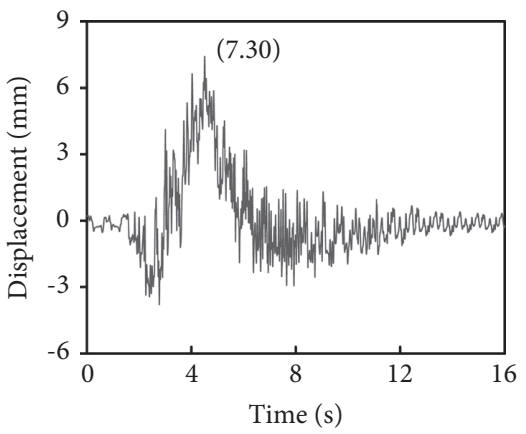

(e)

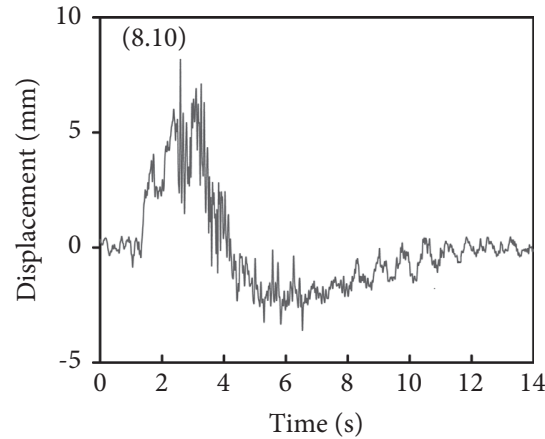

(c)

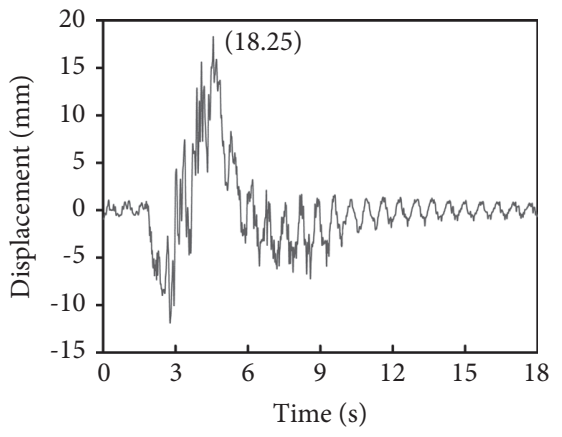

(f)

FIGURE 6: ADR of the original model. (a) RSN56 (130) with E1. (b) RSN56 (130) with E2. (c) RSN900 with E1. (d) RSN900 with E2. (e) RSN74 with E1. (f) RSN74 with E2.

TABle 6: Statistics of the dynamic response.

\begin{tabular}{|c|c|c|c|c|c|c|c|}
\hline \multirow{2}{*}{ Types } & \multirow{2}{*}{ RSN } & \multirow{2}{*}{ Peak acceleration } & \multirow{2}{*}{$\mathrm{ADR}(\mathrm{mm})$} & \multirow{2}{*}{ RMS-ADR (mm) } & \multirow{2}{*}{$\mathrm{AR}\left(\mathrm{m} / \mathrm{s}^{2}\right)$} & \multicolumn{2}{|c|}{$\mathrm{SR}(\mu \varepsilon)$} \\
\hline & & & & & & Bottom-S1 & Top-S4 \\
\hline \multirow{8}{*}{ Site-II } & $56(130)$ & \multirow{3}{*}{$0.35 \mathrm{~g}$} & 6.70 & 2.37 & 1.73 & 28.48 & 117.61 \\
\hline & $56(220)$ & & 2.52 & 0.84 & 1.27 & 14.17 & 66.54 \\
\hline & 83 & & 4.63 & 1.86 & 1.62 & 23.14 & 96.63 \\
\hline & Average & \multirow[t]{2}{*}{-} & 4.62 & 1.69 & 1.54 & 21.93 & 93.59 \\
\hline & $56(130)$ & & 9.67 & 4.77 & 4.21 & 63.24 & 378.65 \\
\hline & $56(220)$ & \multirow[t]{2}{*}{$1.00 \mathrm{~g}$} & 5.44 & 3.39 & 3.48 & 49.45 & 273.23 \\
\hline & 83 & & 8.50 & 4.66 & 4.00 & 60.59 & 349.66 \\
\hline & Average & - & 7.87 & 4.27 & 3.90 & 57.76 & 333.85 \\
\hline \multirow{8}{*}{ NFPT } & 2457 & \multirow{3}{*}{$0.35 \mathrm{~g}$} & 4.68 & 1.62 & 3.01 & 30.71 & 207.97 \\
\hline & 900 & & 8.10 & 2.64 & 5.13 & 54.63 & 387.68 \\
\hline & 6911 & & 6.02 & 2.03 & 4.30 & 46.38 & 262.29 \\
\hline & Average & \multirow[t]{2}{*}{ - } & 6.27 & 2.10 & 4.15 & 43.91 & 285.98 \\
\hline & 2457 & & 7.79 & 3.74 & 7.01 & 130.75 & 843.62 \\
\hline & 900 & \multirow[t]{2}{*}{$1.00 \mathrm{~g}$} & 17.90 & 5.6 & 12.07 & 193.72 & 1331.92 \\
\hline & 6911 & & 9.93 & 4.57 & 10.19 & 145.08 & 755.22 \\
\hline & Average & - & 11.87 & 4.64 & 9.76 & 156.52 & 976.92 \\
\hline \multirow{8}{*}{ LP } & 69 (249) & \multirow{3}{*}{$0.35 \mathrm{~g}$} & 7.57 & 2.33 & 3.56 & 62.33 & 358.25 \\
\hline & 74 & & 7.30 & 2.52 & 5.27 & 70.78 & 416.33 \\
\hline & $90(132)$ & & 6.91 & 1.89 & 4.79 & 70.12 & 407.38 \\
\hline & Average & \multirow[t]{2}{*}{ - } & 7.26 & 2.25 & 4.54 & 67.74 & 393.99 \\
\hline & 69 (249) & & 16.72 & 4.42 & 10.29 & 156.52 & 1004.33 \\
\hline & 74 & \multirow[t]{2}{*}{$1.00 \mathrm{~g}$} & 18.25 & 5.91 & 13.16 & 239.93 & 1646.60 \\
\hline & $90(132)$ & & 11.03 & 4.17 & 12.81 & 191.00 & 1482.56 \\
\hline & Average & - & 15.33 & 4.83 & 12.09 & 195.82 & 1377.83 \\
\hline
\end{tabular}


TABLE 7: First-order frequency of each model $(\mathrm{Hz})$.

\begin{tabular}{|c|c|c|c|c|c|c|c|}
\hline \multirow[t]{2}{*}{ Model } & \multirow[t]{2}{*}{ Before the test } & \multicolumn{3}{|c|}{$\begin{array}{l}\text { With DTMDs in different } \\
\text { boundary conditions }\end{array}$} & \multirow[t]{2}{*}{ After the test } & \multirow[t]{2}{*}{ DTMD } & \multirow[t]{2}{*}{ Case-III } \\
\hline & & Case-III & Case-II & Case-I & & & \\
\hline First-order frequency & 1.64 & 1.53 & 1.56 & 1.58 & 1.67 & First-order frequency & 1.60 \\
\hline
\end{tabular}

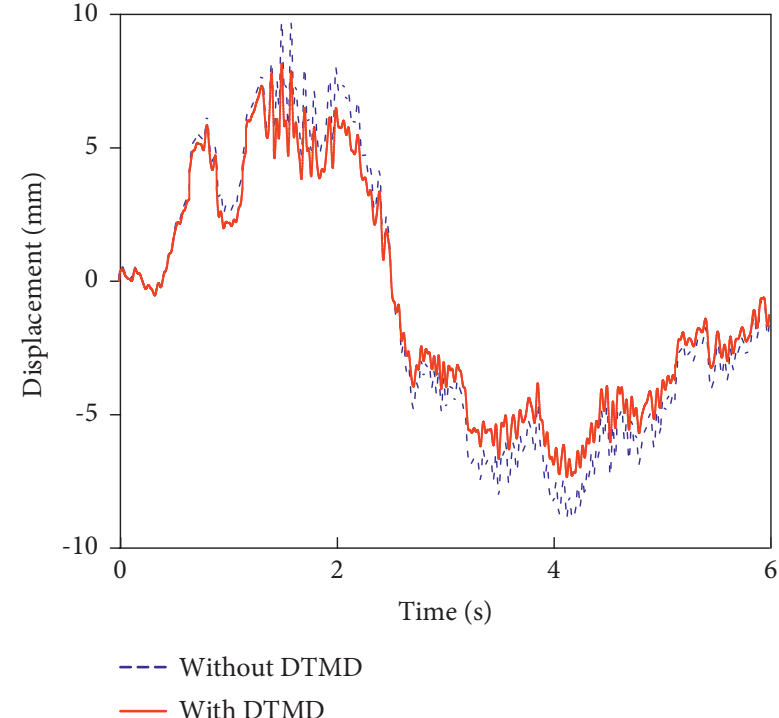

(a)

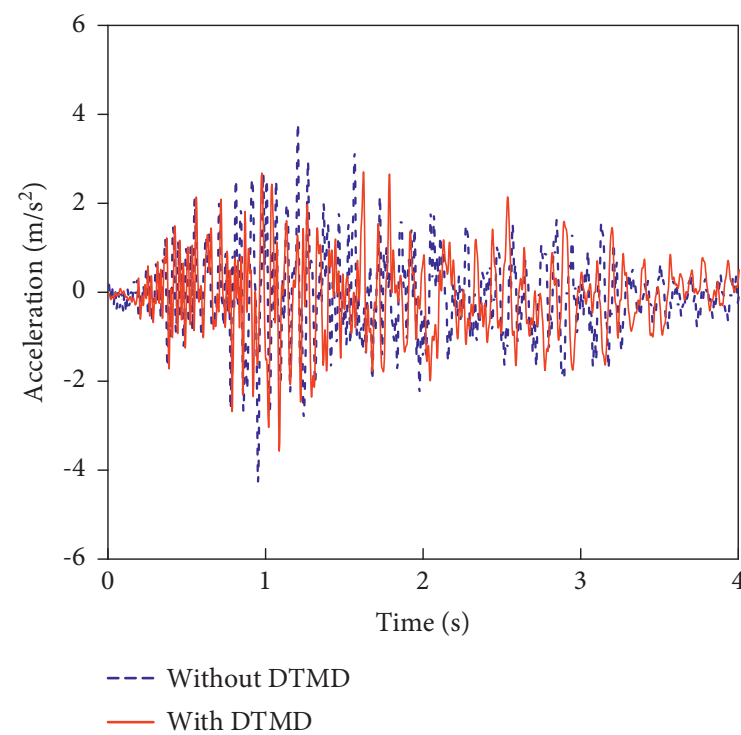

(b)

FIgURE 7: ADR and AR of the model before and after the DTMD installation under the Site-II ground motions (case-III, E2). (a) Absolute displacement. (b) Acceleration.

TABLE 8: Decreasing ratios of the model with the DTMD under Site-II ground motions.

\begin{tabular}{|c|c|c|c|c|c|c|c|c|c|c|c|}
\hline \multirow{2}{*}{ Parameters } & \multirow{2}{*}{ RSN } & \multirow{2}{*}{ Peak (g) } & \multicolumn{3}{|c|}{ Connection cases } & \multicolumn{6}{|c|}{ Decreasing ratio $(\%)$} \\
\hline & & & $\mathrm{I}$ & II & III & $\mathrm{I}$ & Average & II & Average & III & Average \\
\hline \multirow{6}{*}{$\mathrm{ADR}(\mathrm{mm})$} & $56(130)$ & \multirow{3}{*}{0.35} & 6.28 & 6.11 & 5.89 & 6.3 & \multirow{3}{*}{6.0} & 8.8 & \multirow{3}{*}{9.0} & 12.1 & \multirow{3}{*}{11.1} \\
\hline & $56(220)$ & & 2.37 & 2.37 & 2.27 & 5.9 & & 5.8 & & 9.8 & \\
\hline & 83 & & 4.36 & 4.06 & 4.10 & 5.8 & & 12.4 & & 11.5 & \\
\hline & $56(130)$ & \multirow{3}{*}{1.00} & 8.64 & 8.47 & 8.14 & 10.7 & \multirow{3}{*}{5.6} & 12.4 & \multirow{3}{*}{11.1} & 15.8 & \multirow{3}{*}{15.0} \\
\hline & $56(220)$ & & 5.66 & 4.82 & 4.76 & -4.1 & & 11.4 & & 12.5 & \\
\hline & 83 & & 7.63 & 7.69 & 7.09 & 10.2 & & 9.6 & & 16.6 & \\
\hline \multirow{6}{*}{ RMS-ADR (mm) } & $56(130)$ & \multirow{6}{*}{1.00} & 2.14 & 2.15 & 2.05 & 9.7 & \multirow{3}{*}{7.1} & 9.4 & \multirow{3}{*}{9.7} & 13.6 & \multirow{3}{*}{11.6} \\
\hline & $56(220)$ & & 0.77 & 0.76 & 0.76 & 7.9 & & 9.4 & & 9.4 & \\
\hline & 83 & & 1.79 & 1.67 & 1.64 & 3.6 & & 10.3 & & 11.9 & \\
\hline & $56(130)$ & & 4.17 & 4.06 & 3.95 & 12.6 & \multirow{3}{*}{10.0} & 14.9 & \multirow{3}{*}{12.3} & 17.2 & \multirow{3}{*}{14.5} \\
\hline & $56(220)$ & & 3.18 & 3.08 & 3.08 & 6.3 & & 9.1 & & 9.2 & \\
\hline & 83 & & 4.14 & 4.05 & 3.86 & 11.2 & & 13.0 & & 17.1 & \\
\hline \multirow{6}{*}{$\operatorname{AR}\left(\mathrm{m} / \mathrm{s}^{2}\right)$} & $56(130)$ & \multirow{6}{*}{1.00} & 1.60 & 1.55 & 1.53 & 7.8 & \multirow{3}{*}{6.5} & 10.5 & & 11.8 & \multirow{3}{*}{10.5} \\
\hline & $56(220)$ & & 1.20 & 1.22 & 1.16 & 5.4 & & 3.9 & 7.7 & 8.7 & \\
\hline & 83 & & 1.52 & 1.48 & 1.44 & 6.4 & & 8.8 & & 11.0 & \\
\hline & $56(130)$ & & 3.80 & 3.65 & 3.52 & 9.8 & \multirow{3}{*}{7.5} & 13.2 & & 16.4 & \multirow{3}{*}{13.7} \\
\hline & $56(220)$ & & 3.31 & 3.14 & 3.14 & 4.9 & & 9.8 & 11.3 & 9.7 & \\
\hline & 83 & & 3.69 & 3.56 & 3.39 & 7.9 & & 11.0 & & 15.1 & \\
\hline \multirow{6}{*}{$\mathrm{SR}(\mu \varepsilon)$} & $56(130)$ & & 107.65 & 105.28 & 104.55 & 8.5 & \multirow{3}{*}{6.5} & 10.5 & & 11.1 & \\
\hline & $56(220)$ & 0.35 & 62.27 & 60.67 & 59.43 & 6.4 & & 8.8 & 8.9 & 10.7 & 10.3 \\
\hline & 83 & & 92.35 & 89.59 & 87.83 & 4.5 & & 7.3 & & 9.1 & \\
\hline & $56(130)$ & & 330.13 & 323.42 & 312.34 & 12.8 & & 14.6 & & 17.5 & \\
\hline & $56(220)$ & 1.00 & 246.15 & 245.06 & 244.30 & 9.9 & 11.1 & 10.3 & 12.9 & 10.6 & 14.5 \\
\hline & 83 & & 312.19 & 301.52 & 295.63 & 10.7 & & 13.8 & & 15.5 & \\
\hline
\end{tabular}


the decreasing ratios of the model with the DTMD under the Site-II ground motions.

As shown in Table 8, except for a few cases under case-I, the DTMD can provide a good damping effect. Taking the RSN56 (130) wave under the E2 earthquake as an example, the decreasing ratios of the ADR, RMS-ADR, AR, and SR of the test model under case-III are $15.8 \%, 17.2 \%, 16.4 \%$, and $17.5 \%$, respectively.

The average decreasing ratio of each dynamic response parameter basically follows the variation law that decreasing ratios are the largest under case-III, the second largest under case-II, and the smallest under case-I. Taking the RMS-ADR parameter under the E2 earthquake as an example, the average decreasing ratio of the DTMD with case-I is only $10.0 \%$. However, the corresponding decreasing ratios of the DTMD with case-II and case-III are $12.3 \%$ and $14.5 \%$, respectively. The experimental results are similar to the optimisation results; that is, the smaller damping ratio of the connection will lead to a better damping effect for the DTMD. Based on the experimental phenomena, the reason may be that the response amplitude of the DTMD decreases with an increase in the damping of the upper TMD. The energy absorption capacity of the DTMD was significantly impacted by the damping ratio of the upper tuned mass damper (described in detail in Section 4.2.5).

In addition, the damping effect of the DTMD is also influenced by the excitation intensity. The larger excitation intensity will lead a better damping effect of the DTMD. Taking case-III as an example, under E1 and E2 excitations, the average decreasing ratios of the ADR, RMS-ADR, AR, and SR of the DTMD are $11.1 \%$ and $15.0 \%, 11.6 \%$ and $14.5 \%$, $10.5 \%$ and $13.7 \%$, and $10.3 \%$ and $14.5 \%$, respectively. This is related to the damping mechanism of the TMD [14,27-30]. With an increase in the excitation amplitude, the structural response is greater and the dynamic response and energy dissipation of the DTMD increase.

\subsubsection{Near-Fault Pulse-Type (NFPT) Ground Motions.} Figure 8 shows a comparison of dynamic response of the model before and after the DTMD installation under a typical NFPT ground motion of RSN900. The connection condition was case-III.

As Figure 8 shows, when the time of earthquake excitation is less than $0.5 \mathrm{~s}$, the absolute displacement of the test model is less than $8 \mathrm{~mm}$ and the control effect of the DTMD on the displacement response is not evident. When the acceleration response of the test model is less than $5 \mathrm{~m} / \mathrm{s}^{2}$ (the time of earthquake excitation $<0.3 \mathrm{~s}$ ), the control effect of the DTMD on the acceleration response is also not evident. However, after a period of earthquake excitation, the DTMD will not only decrease the ADR and AR of the model but will also rapidly attenuate its dynamic response. The DTMD has a time delay before providing the damping effect. Table 9 lists the dynamic response and decreasing ratios of the model with the DTMD under the NFPT ground motions.

As shown in Table 9, the DTMD has an obvious damping effect for the model under NFPT ground motions and the damping effect of the DTMD under RSN900 is the most significant. Taking case-III under the E2 earthquake as an example, the decreasing ratios of the ADR, RMS-ADR, AR, and SR under the RSN900 wave reach 22.8\%, 24.9\%, 25.0\%, and $22.1 \%$, respectively, which are significantly higher than the corresponding values under the other NFPT ground motions. That is, when the VPP of the NFPT ground motion is close to the natural vibration period of the structure, the dynamic response of the structure amplified and then the DTMD will provide better damping effect.

The influence law of a DTMD with different boundary cases under the NFPT ground motions is similar to that under the Site-II ground motions. The DTMD has the best damping effect under case-III and a poor damping effect under case-I. Taking the ARs under the E2 excitation as an example, the average decreasing ratio of the DTMD with case-I is only $10.9 \%$. In contrast, the corresponding average decreasing ratios of the DTMDs with case-II and case-III are $15.1 \%$ and $19.0 \%$, respectively. The decreasing ratios of each dynamic response parameter increase with increasing excitation intensity. Taking case-III as an example, under E1 and E2 excitations, the average decreasing ratios of the ADR and RMS-ADR increase from $12.6 \%$ to $17.3 \%$ and $13.0 \%$ to $20.4 \%$, respectively. In this case, the average decreasing ratios of the AR and SR increase from $12.4 \%$ to $19.0 \%$ and $12.7 \%$ to $17.5 \%$, respectively.

4.2.4. Long-Period (LP) Ground Motions. Figures 9(a) and 9(b) show the ADR and AR of the model before and after the DTMD installation under the RNS74 wave of case-III.

Figure 9 shows that the DTMD can obviously decrease the amplitude of ADR and AR of the model under the LP ground motions. The dynamic response and decreasing ratios of the model with the DTMD under LP ground motions are presented in Table 10.

As shown in Table 10, except for the negative decreasing rate in a few cases, the DTMD can provide good energy dissipation capacity under LP ground motions. Taking case-III under E2 excitation as an example, the decreasing ratio of each dynamic response of the test model is more than $22 \%$ under the RSN74. Similar to the boundary condition law under the NFPT ground motions and Site-II ground motions, the damping effect of the DTMD will be limited when the damping ratio of the connection increases. Taking the RMS-ADR under the E2 excitation as an example, the average decreasing ratio of the DTMD with case-I is only $15.2 \%$. However, the corresponding average decreasing ratios of the DTMDs with cases II and III are $20.1 \%$ and $23.7 \%$, respectively. The excitation intensity also has the same influence law as that under the NFPT and Site-II ground motions, and the decreasing rates of each dynamic parameter under the LP ground motions increase with an increase in excitation intensity. Taking case-III as an example, the average decreasing ratios of the ADR, RMS-ADR, AR, and SR under the E1 excitation are $13.6 \%, 14.5 \%, 13.7 \%$, and $13.6 \%$, respectively. In contrast, the corresponding decreasing ratios of the DTMD are up to $21.1 \%, 23.7 \%, 22.4 \%$, and $22.1 \%$ under the E2 excitation, respectively. 


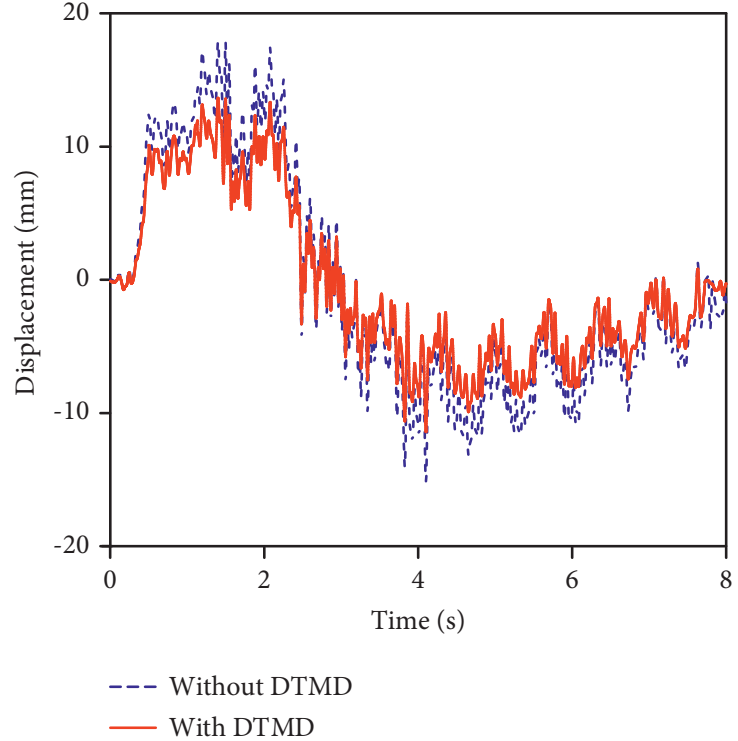

(a)

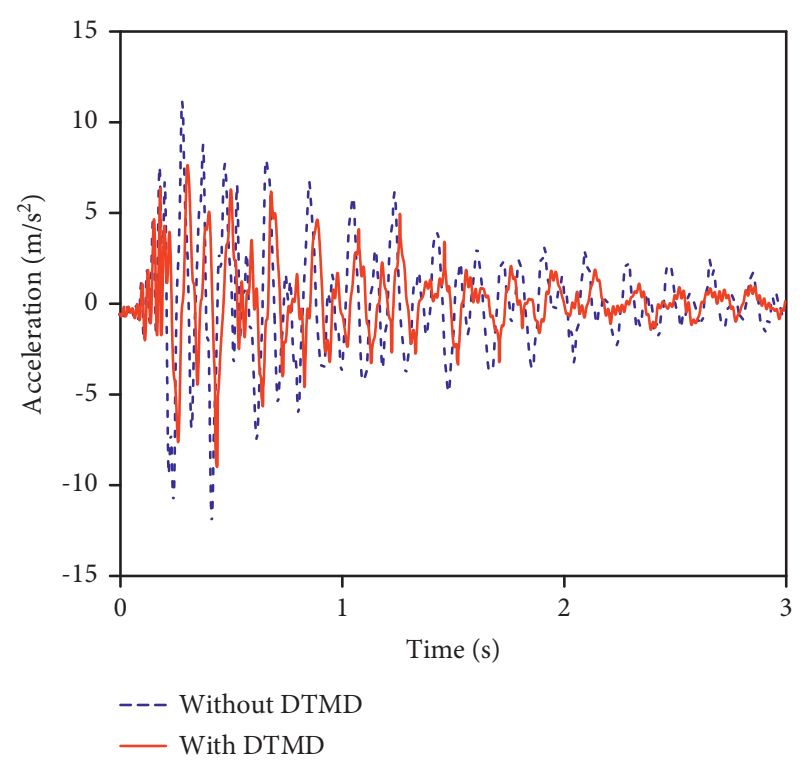

(b)

FIGURE 8: ADR and AR of the model before and after the DTMD installation under the NFPT ground motions (case-III, E2). (a) Absolute displacement. (b) Acceleration.

TABLE 9: Decreasing ratios of the model with DTMD under NFPT ground motions.

\begin{tabular}{|c|c|c|c|c|c|c|c|c|c|c|c|}
\hline \multirow{2}{*}{ Parameters } & \multirow{2}{*}{ RSN } & \multirow{2}{*}{ Peak (g) } & \multicolumn{3}{|c|}{ Connection cases } & \multicolumn{6}{|c|}{ Decreasing ratio (\%) } \\
\hline & & & $\mathrm{I}$ & II & III & $\mathrm{I}$ & Average & II & Average & III & Average \\
\hline \multirow{6}{*}{$\mathrm{ADR}(\mathrm{mm})$} & 2457 & \multirow{3}{*}{0.35} & 4.31 & 4.27 & 4.23 & 7.9 & \multirow{3}{*}{8.9} & 8.8 & & 9.6 & \multirow{3}{*}{12.6} \\
\hline & 900 & & 7.23 & 6.95 & 6.80 & 10.8 & & 14.2 & 11.3 & 16.1 & \\
\hline & 6911 & & 5.53 & 5.37 & 5.30 & 8.1 & & 10.8 & & 12.0 & \\
\hline & 2457 & \multirow{3}{*}{1.00} & 7.31 & 6.99 & 6.65 & 6.2 & \multirow{3}{*}{10.4} & 10.2 & \multirow{3}{*}{13.7} & 14.6 & \multirow{3}{*}{17.3} \\
\hline & 900 & & 15.18 & 14.46 & 13.81 & 15.2 & & 19.2 & & 22.8 & \\
\hline & 6911 & & 8.96 & 8.77 & 8.48 & 9.7 & & 11.7 & & 14.6 & \\
\hline \multirow{6}{*}{ RMS-ADR (mm) } & 2457 & \multirow{3}{*}{0.35} & 1.49 & 1.46 & 1.45 & 7.8 & \multirow{3}{*}{9.1} & 9.6 & & 10.3 & \multirow{3}{*}{13.0} \\
\hline & 900 & & 2.36 & 2.31 & 2.23 & 10.5 & & 12.6 & 11.5 & 15.5 & \\
\hline & 6911 & & 1.85 & 1.78 & 1.76 & 8.9 & & 12.4 & & 13.1 & \\
\hline & 2457 & \multirow{3}{*}{1.00} & 3.32 & 3.26 & 3.17 & 11.3 & \multirow{3}{*}{12.9} & 12.8 & & 15.1 & \multirow{3}{*}{20.4} \\
\hline & 900 & & 4.75 & 4.39 & 4.20 & 15.1 & & 21.6 & 16.9 & 24.9 & \\
\hline & 6911 & & 4.01 & 3.82 & 3.60 & 12.3 & & 16.3 & & 21.2 & \\
\hline \multirow{6}{*}{$\mathrm{AR}\left(\mathrm{m} / \mathrm{s}^{2}\right)$} & 2457 & & 2.93 & 3.03 & 2.79 & 2.7 & \multirow{3}{*}{8.3} & -0.6 & & 7.1 & \multirow{3}{*}{12.4} \\
\hline & 900 & 0.35 & 4.51 & 4.39 & 4.26 & 12.0 & & 14.5 & 8.7 & 16.9 & \\
\hline & 6911 & & 3.86 & 3.78 & 3.74 & 10.2 & & 12.1 & & 13.1 & \\
\hline & 2457 & \multirow{3}{*}{1.00} & 6.38 & 6.29 & 5.97 & 8.9 & \multirow{3}{*}{10.9} & 10.3 & & 14.8 & \multirow{3}{*}{19.0} \\
\hline & 900 & & 10.50 & 9.73 & 9.05 & 13.0 & & 19.4 & 15.1 & 25.0 & \\
\hline & 6911 & & 9.08 & 8.60 & 8.45 & 10.9 & & 15.6 & & 17.1 & \\
\hline \multirow{6}{*}{$\mathrm{SR}(\mu \varepsilon)$} & 2457 & \multirow{3}{*}{0.35} & 193.21 & 190.85 & 187.91 & 7.1 & \multirow{3}{*}{8.8} & 8.2 & & 9.6 & \multirow{3}{*}{12.7} \\
\hline & 900 & & 346.53 & 339.29 & 325.85 & 10.6 & & 12.5 & 10.3 & 15.9 & \\
\hline & 6911 & & 239.11 & 235.30 & 229.45 & 8.8 & & 10.3 & & 12.5 & \\
\hline & 2457 & & 745.11 & 717.58 & 721.65 & 11.7 & & 14.9 & & 14.5 & \\
\hline & 900 & 1.00 & 1143.42 & 1055.55 & 1037.37 & 14.2 & 12.8 & 20.8 & 16.2 & 22.1 & 17.5 \\
\hline & 6911 & & 660.44 & 656.81 & 634.22 & 12.5 & & 13.0 & & 16.0 & \\
\hline
\end{tabular}

4.2.5. Comparison of the Damping Effect of DTMD under Three Types of Ground Motions. To further study the damping effect of the DTMD under the three types of ground motions, Figure 10 provides a comparison of the average decreasing ratios of the DTMD with different connection cases and under different ground motions.
As shown in Figure 10, except for some cases under case-I, the damping effect of the DTMD under the LP ground motions is better than that under the NFPT and Site-II ground motions; among the three, the damping effect of the DTMD under Site-II ground motions is relatively poor. In addition, the larger excitation intensity 


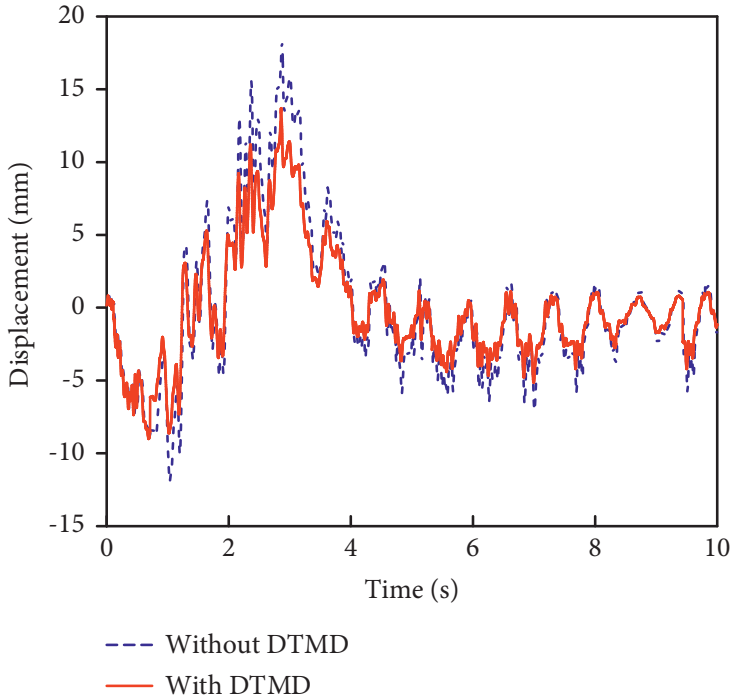

(a)

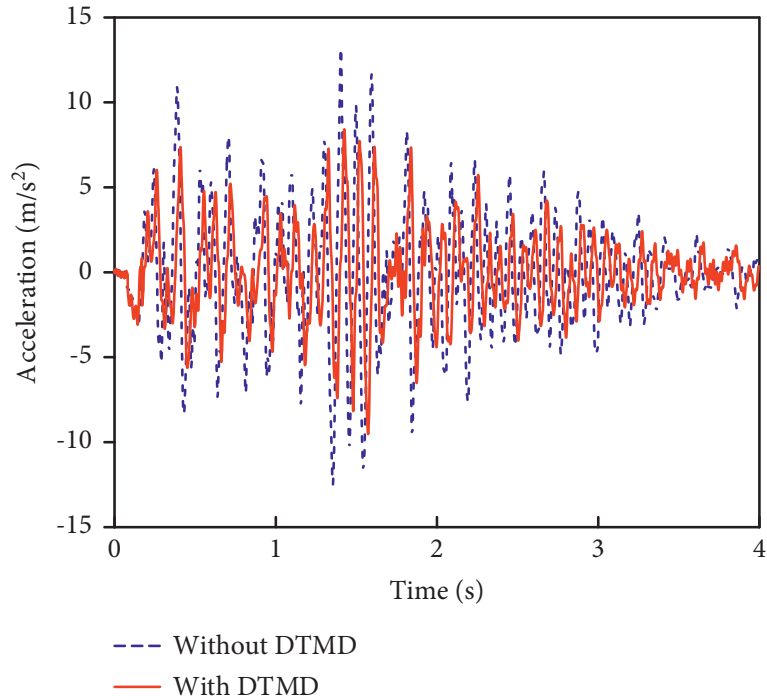

(b)

FIGURE 9: ADR and AR of the model with and without the DTMD under the LP ground motions (case-III, E2). (a) Absolute displacement. (b) Acceleration.

TABLE 10: Decreasing ratios of the model with DTMD under LP ground motions.

\begin{tabular}{|c|c|c|c|c|c|c|c|c|c|c|c|}
\hline \multirow{2}{*}{ Parameters } & \multirow{2}{*}{ RSN } & \multirow{2}{*}{ Peak (g) } & \multicolumn{3}{|c|}{ Connection cases } & \multicolumn{6}{|c|}{ Decreasing ratio $(\%)$} \\
\hline & & & $\mathrm{I}$ & II & III & I & Average & II & Average & III & Average \\
\hline \multirow{6}{*}{$\mathrm{ADR}(\mathrm{mm})$} & $69(249)$ & \multirow{3}{*}{0.35} & 6.88 & 6.74 & 6.72 & 9.1 & \multirow{3}{*}{10.1} & 10.9 & \multirow{3}{*}{11.6} & 11.2 & \multirow{3}{*}{13.6} \\
\hline & 74 & & 6.49 & 6.37 & 6.15 & 11.1 & & 12.7 & & 15.8 & \\
\hline & $90(132)$ & & 6.21 & 6.14 & 5.95 & 10.2 & & 11.2 & & 13.8 & \\
\hline & $69(249)$ & \multirow{3}{*}{1.00} & 14.74 & 14.58 & 14.23 & 11.8 & \multirow{3}{*}{13.2} & 12.8 & \multirow{3}{*}{18.1} & 14.9 & \multirow{3}{*}{21.1} \\
\hline & 74 & & 15.14 & 14.24 & 13.74 & 17.1 & & 22.0 & & 24.7 & \\
\hline & $90(132)$ & & 9.86 & 8.87 & 8.41 & 10.6 & & 19.5 & & 23.8 & \\
\hline \multirow{6}{*}{ RMS-ADR (mm) } & $69(249)$ & \multirow{3}{*}{0.35} & 2.10 & 2.02 & 1.98 & 9.9 & \multirow{3}{*}{10.0} & 13.4 & \multirow{3}{*}{12.9} & 15.1 & \multirow{3}{*}{14.5} \\
\hline & 74 & & 2.24 & 2.12 & 2.11 & 11.0 & & 15.8 & & 16.5 & \\
\hline & $90(132)$ & & 1.72 & 1.71 & 1.66 & 9.0 & & 9.4 & & 12.0 & \\
\hline & $69(249)$ & \multirow{3}{*}{1.00} & 3.83 & 3.67 & 3.46 & 13.4 & \multirow{3}{*}{15.2} & 17.0 & & 21.7 & \multirow{3}{*}{23.7} \\
\hline & 74 & & 5.00 & 4.60 & 4.33 & 15.4 & & 22.1 & 20.1 & 26.8 & \\
\hline & $90(132)$ & & 3.47 & 3.28 & 3.22 & 16.7 & & 21.2 & & 22.7 & \\
\hline \multirow{6}{*}{$\operatorname{AR}\left(\mathrm{m} / \mathrm{s}^{2}\right)$} & 69 (249) & \multirow{3}{*}{0.35} & 3.57 & 3.39 & 3.24 & -0.3 & \multirow{3}{*}{8.2} & 4.8 & & 9.1 & \multirow{3}{*}{13.7} \\
\hline & 74 & & 4.55 & 4.52 & 4.40 & 13.6 & & 14.2 & 10.7 & 16.5 & \\
\hline & 90 (132) & & 4.25 & 4.16 & 4.04 & 11.3 & & 13.1 & & 15.6 & \\
\hline & 69 (249) & \multirow{3}{*}{1.00} & 9.31 & 9.12 & 8.44 & 9.5 & \multirow{3}{*}{13.6} & 11.3 & & 17.9 & \multirow{3}{*}{22.4} \\
\hline & 74 & & 10.82 & 9.92 & 9.47 & 17.8 & & 24.6 & 18.4 & 28.0 & \\
\hline & 90 (132) & & 11.09 & 10.34 & 10.08 & 13.4 & & 19.3 & & 21.3 & \\
\hline \multirow{6}{*}{$\operatorname{SR}(\mu \varepsilon)$} & $69(249)$ & & 329.84 & 317.44 & 316.58 & 7.9 & & 11.4 & & 11.6 & \\
\hline & 74 & 0.35 & 364.71 & 353.18 & 352.34 & 12.4 & 10.2 & 15.2 & 12.9 & 15.4 & 13.6 \\
\hline & $90(132)$ & & 365.57 & 357.60 & 351.39 & 10.3 & & 12.2 & & 13.7 & \\
\hline & 69 (249) & & 846.33 & 824.36 & 803.16 & 15.7 & & 17.9 & & 20.0 & \\
\hline & 74 & 1.00 & 1427.85 & 1310.53 & 1269.36 & 13.3 & 14.5 & 20.4 & 20.1 & 22.9 & 22.1 \\
\hline & $90(132)$ & & 1267.53 & 1157.73 & 1134.60 & 14.5 & & 21.9 & & 23.5 & \\
\hline
\end{tabular}

(more significant dynamic response) will lead to a better damping effect for the DTMD. For the LP ground motions and Site-II ground motions under case-III, the differences in the average decreasing rates of the ADR, RMS-ADR, AR, and SR under E1 excitation are 2.5\%, 2.9\%, 3.2\%, and 3.3\%, respectively. However, the corresponding differences reach $6.2 \%, 9.2 \%, 8.7 \%$, and $7.6 \%$ under E2 excitation, respectively. Similarly, there is little difference between the LP ground motions and NFPT ground motions in regards to the decreasing ratios of the DTMD for the above parameters under the E1 excitation. However, under the E2 excitation, the damping effect of the DTMD under LP ground motions is evidently better than that under NFPT ground motions. Taking case-III as an example, the difference between the average decreasing ratios of the DTMD under the NFPT ground motions and the LP ground 


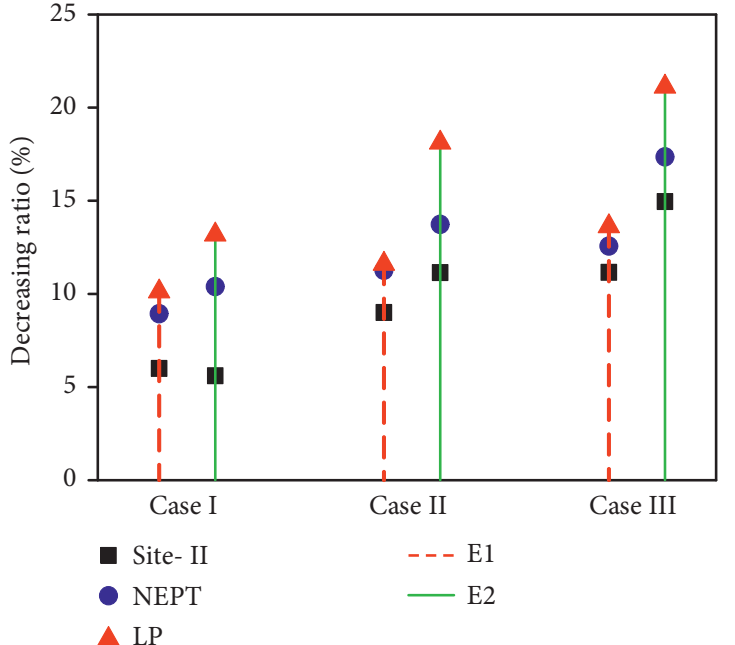

(a)

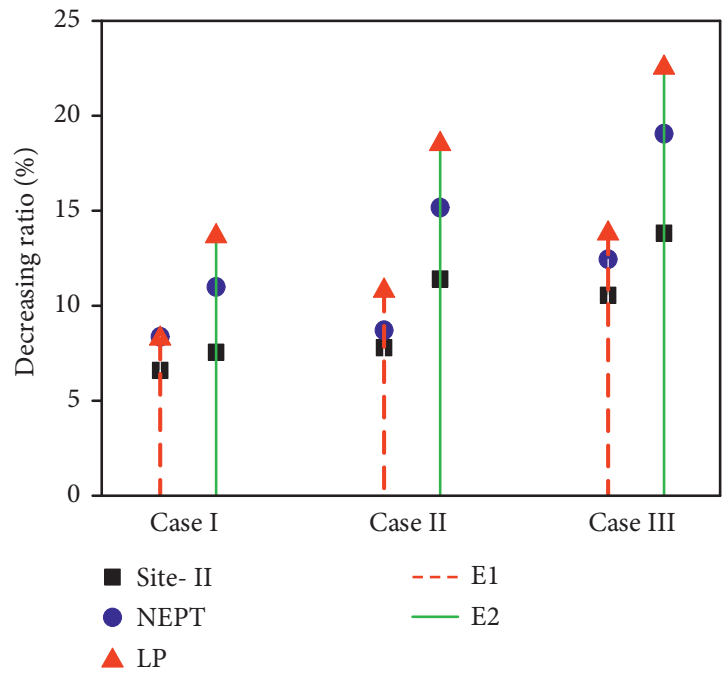

(c)

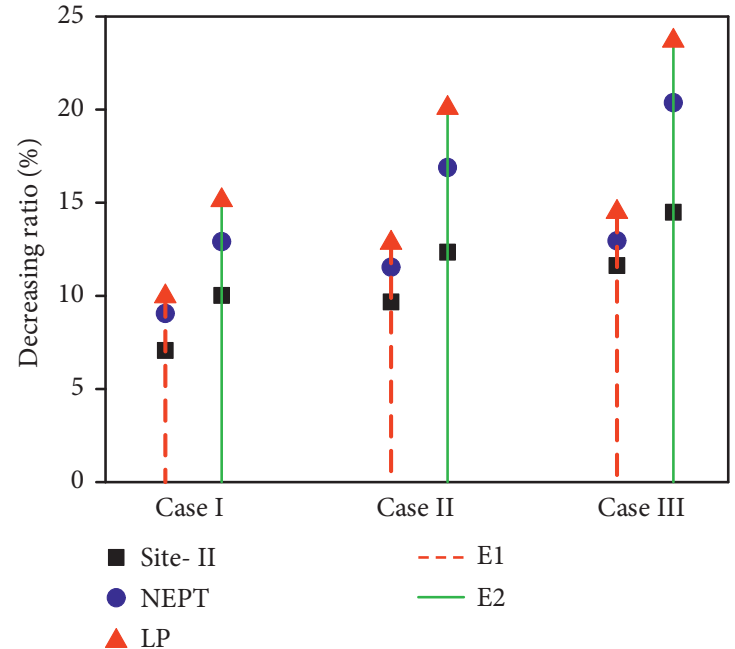

(b)

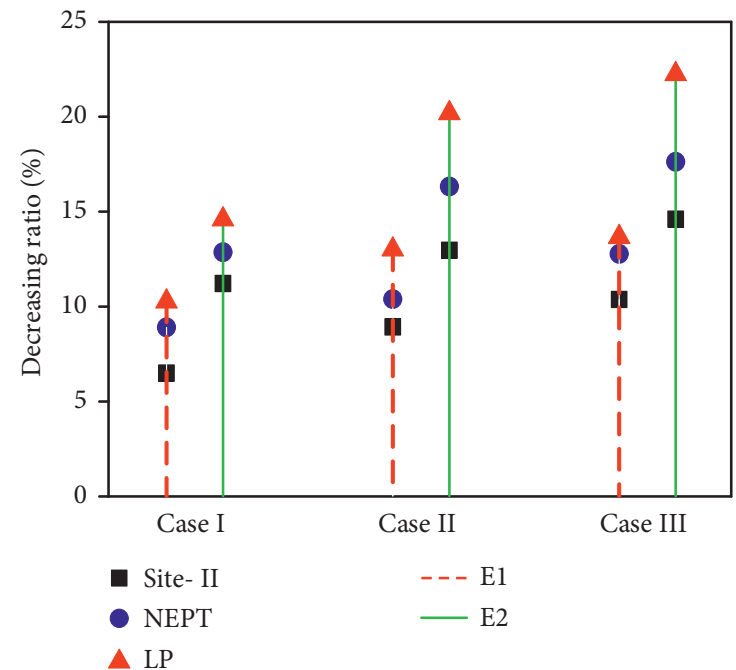

(d)

Figure 10: Comparison of the damping effect of the DTMD. (a) ADR. (b) RMS-ADR. (c) AR. (d) SR.

motions is in the range of $0.9 \%$ to $1.5 \%$ under the $\mathrm{E} 1$ excitation. However, the corresponding difference reaches $3.3 \%$ to $4.6 \%$ under the $\mathrm{E} 2$ excitation. In addition, the damping effect of the DTMD under NFPT ground motions is also evidently better than that under Site-II ground motions. Except for individual parameters in case-I, the difference in the average decreasing rates of the DTMD between them also increases with the increase in excitation intensity. Taking case-III as an example, the difference in the average decreasing ratios between the NFPT and Site-II ground motions under E1 excitation is approximately $1.8 \%$. The corresponding difference reaches $4.1 \%$ under E2 excitation. To further study the damping mechanism of the DTMD, Figures 11(a) and 11(b) show the displacement response time history of the upper TMD under the Site-II ground motion RSN56 (130) and LP ground motion RSN74. Figure 11(c) and 11(d) show a comparison of the ADR decreasing ratios under two typical ground motions with different boundary cases.
As shown in Figures 11(a) and 11(b), the displacement response of the upper TMD under the LP ground motion RSN74 is evidently greater than that under the Site-II ground motion RSN56 (130) and this phenomenon becomes more evident with the increase in excitation intensity. For example, the difference in the displacement amplitude between them under the $\mathrm{E} 1$ condition is $2.94 \mathrm{~mm}$, whereas that under the $\mathrm{E} 2$ condition is $7.03 \mathrm{~mm}$. For the same excitation, the displacement response of the upper TMD under the E2 condition is evidently larger than that under the E1 condition. Taking RSN74 as an example, the displacement amplitudes of the upper TMD under the E1 and E2 conditions are $10.80 \mathrm{~mm}$ and $20.73 \mathrm{~mm}$, respectively.

It can be seen from Figures 11(c) and 11(d) that the smaller damping ratio of the connection will lead a more significant damping capacity of the DTMD. Combined with Figures 11(a) and 11(b), it can also be concluded that the dynamic response of the DTMD has a significant impact on its own damping capacity. A greater response of the upper 


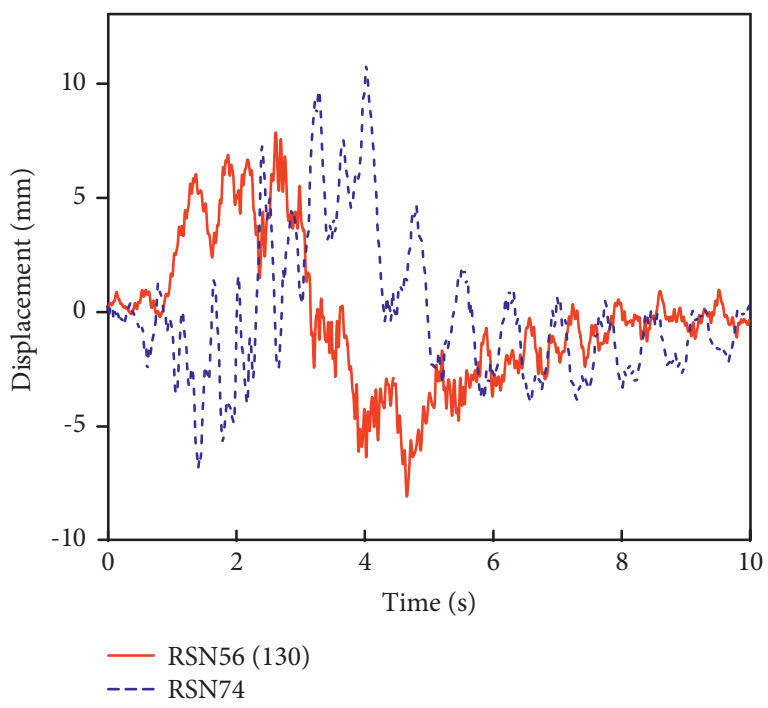

(a)

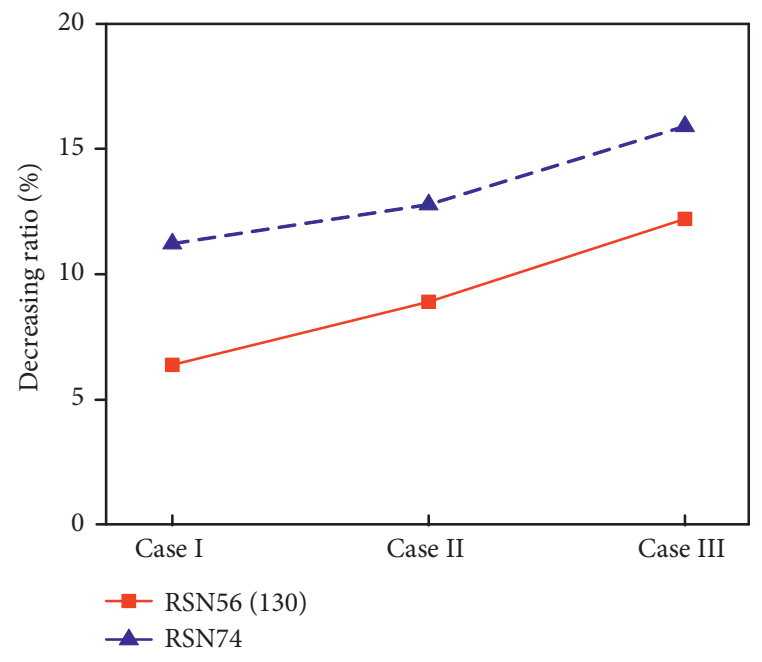

(c)

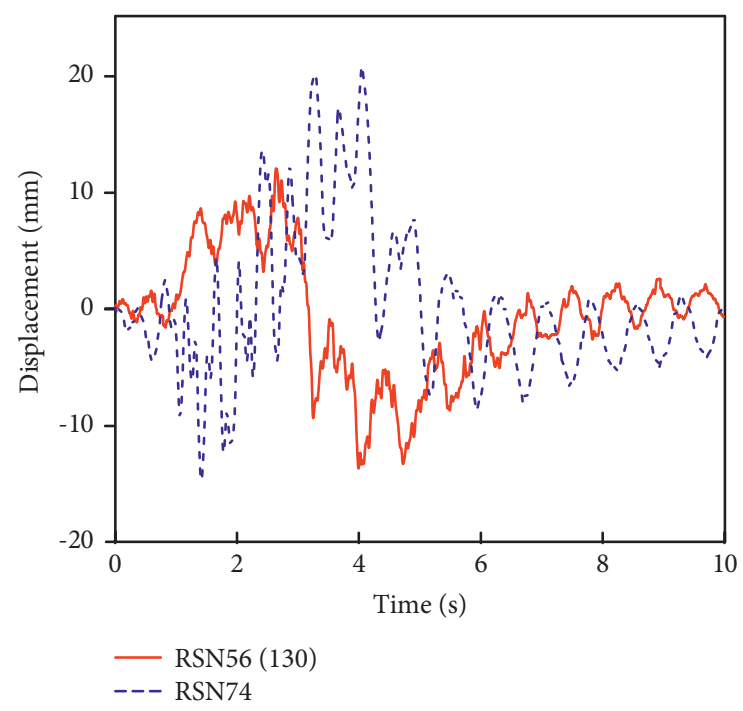

(b)

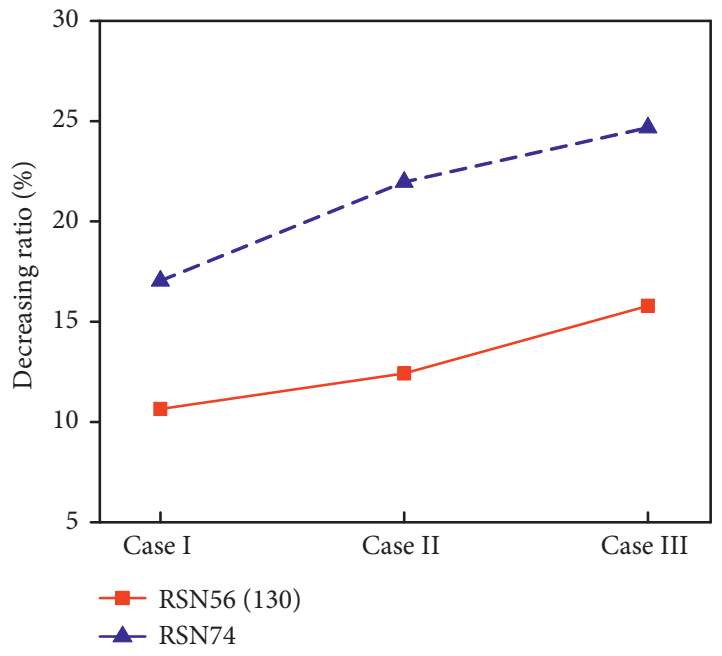

(d)

Figure 11: Comparison of damping effect of DTMD under two typical ground motions. (a) E1 (case-III). (b) E2 (case-III). (c) E1. (d) E2.

TMD will result in a significant damping capacity for the DTMD. Taking case-III under E2 excitation as an example, under the Site-II ground motion RSN56 (130) and LP ground motion RSN74, the decreasing rates of ADR are $15.8 \%$ and $24.7 \%$, respectively. Combined with the analysis in Section 4.1, it can be seen that the dynamic response of the structure underground motions with long-period characteristics (LP and NFPT ground motions) is larger, the corresponding response of DTMD is larger, and the damping effect of the DTMD is better. It can also be seen that the vibration of the DTMD requires a certain duration time through the dynamic response curve of the DTMD itself. For the test results of this study, the response of the DTMD is very small $(<0.5 \mathrm{~mm})$ when the excitation duration is less than $0.5 \mathrm{~s}$, showing that the DTMD requires a certain excitation duration to exert the damping effect. Further optimisation methods for decreasing the time delay of the DTMD damping effect will be the focus of future studies. It should be pointed out that the time delay of the DTMD is also related to the bracketed and energy duration of the ground motion. However, the damping property of the DTMD is mainly affected by the relative dynamic response of the DTMD and the controlled structure. It is much complex to construct the relationship between the bracketed or energy duration of the ground motions and the time delay property of the damping effect of the DTMD.

Moreover, the idea of the mode shape decomposition response method was used to optimize the DTMD [49]. However, the actual seismic response of the HRS is much more complex due to the participation of multiple modes and unharmonic ground motions. Therefore, the actual damping effect of the DTMD may have significant difference with the optimised damping effect. As Tables 8-10 show, the dynamic response of structures may be amplified after the DTMD arrangement under some cases. And, the actual average decreasing rate was in the range of $5 \% \sim 15 \%$. By contrast, the theoretical decreasing ratio of the DDMF for the optimised DTMD can reach $80 \%$ under resonance 
harmonic excitation and the damping effect of the optimised DTMD for the controlled structure can also exceed $50 \%$ after considering the mass participation ratio of the first three modes. Thus, the effectiveness of the parameter optimisation method for the DTMD based on the harmonic excitation is uncertain. In practical seismic design, the nonlinear time history analysis or model testing is required to verify the optimised parameters.

\section{Discussion}

5.1. Comparison of the Damping Effect of UTMD and DTMD for HRSs. To compare the damping effect of the UTMD (with the same mass as the DTMD) and the DTMD for HRSs, shaking table tests of the model with the UTMD were also carried out. The settlement position of the UTMD was selected as the same as the DTMD. The arrangement of the UTMD is shown in Figure 12. The ground motions were selected as the same from the previous description in Table 4. Figure 13 provides the dynamic response time history curves of the model without the damper, with the UTMD, and with the DTMD under typical ground motions. The connection cases of the UTMD and the DTMD were the same and were case-III.

As Figure 13 shows, the UTMD can also effectively reduce the displacement and acceleration response of the model under RSN69 (249). However, the UTMD increases the dynamic response of the model under RSN74. Taking the E2 excitation as an example, the decreasing ratios of the UTMD are $16.1 \%$ and $-12.7 \%$ under RSN69 (249) and RSN74, respectively. However, the DTMD can both effectively decrease the dynamic response of the model. Thus, the damping robustness of the DTMD is better than that of the UTMD. In addition, the response attenuation of the model with the DTMD is faster than that of with the UTMD during the later excitation stage. Figure 14 gives the comparison of the decreasing ratios of the UTMD and the DTMD for the scaled model.

As Figure 14 shows, compared with the average damping effect of DTMD (14.9\% for ADR, 15.5\% for AR), the UTMD has a poorer average damping effect $(2.1 \%$ for ADR, $2.4 \%$ for AR). The DTMD can provide more effective damping effect for HRSs than UTMD. To further analyse the damping effect of the UTMD and the DTMD, Figure 15 provides the comparison of the PSD (power spectral density) for accelerations of the model with the UTMD and the DTMD under typical ground motions.

As Figure 15 shows, the UTMD only has a better damping effect for the first-order vibration of the model. The UTMD cannot provide effective damping effect for higherorder vibration of the model. Thus, the damping robustness of the UTMD is poor. The DTMD can both effectively reduce the first-order vibration response and the higher-order vibration responses of the model. The damping frequency band of the DTMD is significantly larger than that of the UTMD. The reason is that the damping frequency band or robustness of the DTMD is mainly affected by the lower mass damper. The lower tuned mass damper is applied as a tuning system to control the dynamic response of the upper

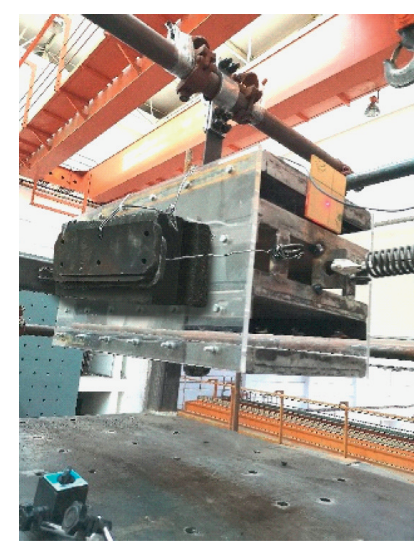

Figure 12: Arrangement of the UTMD.

tuned mass damper which can improve the damping frequency band of the upper tuned mass damper.

\subsection{Method for Obtaining the Equivalent Additional Damping}

Ratio. The equivalent damping ratio of the controlled structure can be approximated by (14) under the free vibration test.

$$
\xi=\frac{1}{2 \pi m} \frac{A_{n}}{A_{n+m}},
$$

where $A_{n}$ and $A_{n+m}$ represent two selected amplitudes separated by $m$ vibration cycles, respectively. $\pi$ is the circular constant. It should be noted that the above calculation method for the equivalent damping ratio can be hardly used in practice. The free vibration test of the practical structure is extremely difficult. Taking the model tower in this study as an example, the height of the test model is $11 \mathrm{~m}$ and the total weight of the model is $32.2 \mathrm{kN}$. It is almost impossible to apply an initial displacement at the top of the test model. On the other hand, it cannot simply use a harmonic excitation or a ground motion to simulate the excitation of an initial displacement. Moreover, the additional damping ratio of the DTMD is related to the dynamic response and damage state of the controlled structure. The equivalent additional damping ratio of the DTMD is nonlinear. Therefore, the equivalent damping ratio of the system cannot be obtained in practice.

At present, the Code for Seismic Design of Buildings (GB 50011-2010) provides the calculation method of the effective damping ratio for displacement-related (metal, frictional dampers, etc.) and velocity-related (viscous, viscoelastic dampers, etc.) energy absorbers. The effective damping ratio of displacement-related and nonlinear velocity-related energy absorbers attached to structures can be estimated by the following equation:

$$
\xi_{a}=\sum_{j} \frac{W_{c j}}{\left(4 \pi W_{s}\right)},
$$

where $\xi_{a}$ denotes the effective damping ratio of the energy absorbers. $W_{c j}$ represents the energy consumed by the $j$-th energy absorber in a loading cycle under an expected 

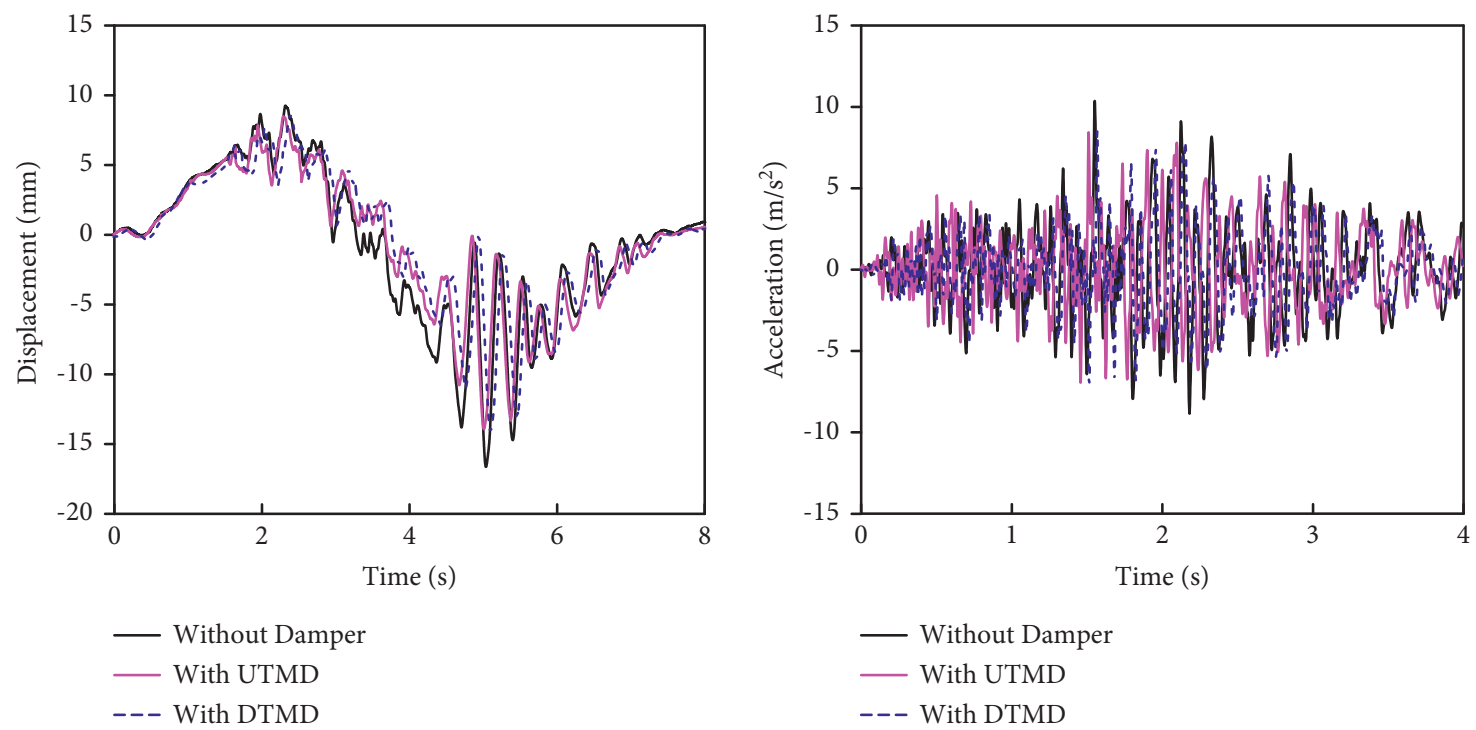

(a)

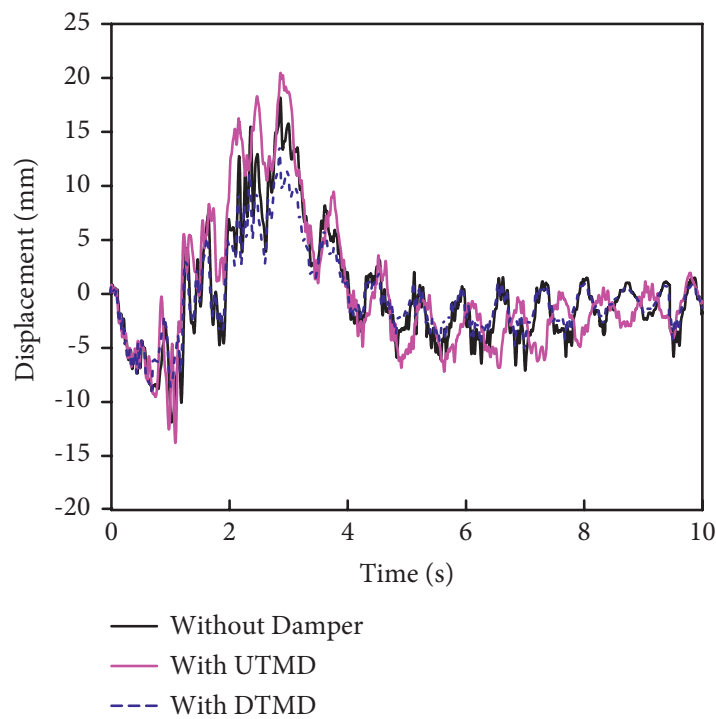

(c)

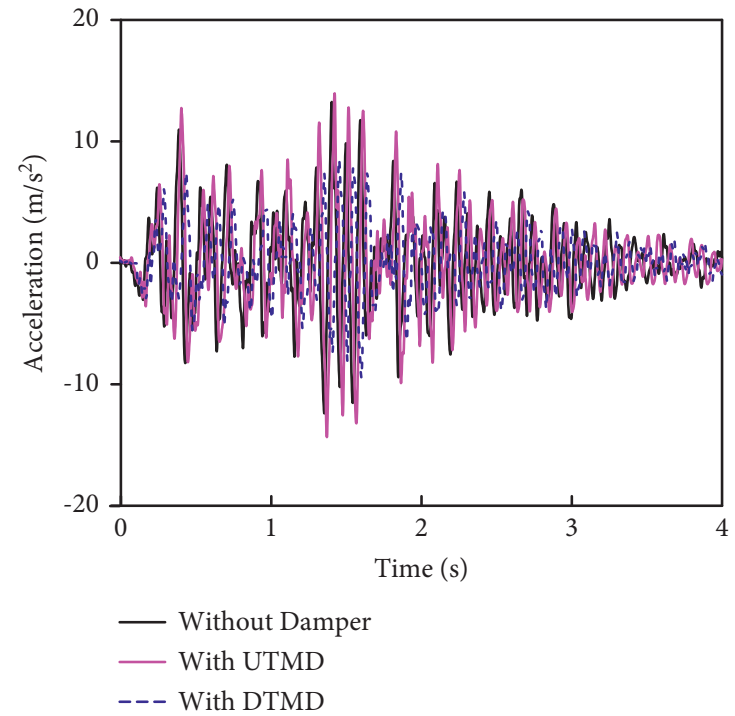

(d)

FIGURE 13: Comparison of the dynamic response time history curves of the model before and after the dampers installation (case-III). (a) ADR (RSN69 (249)). (b) AR (RSN69 (249)). (c) ADR (RSN74). (d) AR (RSN74).

interstory displacement $\Delta u_{j}$. And, $W_{s}$ represents the total strain energy of the structure with energy absorbers under the same expected interstory displacement. In addition, the effective damping ratio of the energy absorbers attached to the structure can be determined by the forced decoupling method when the energy absorbers distribute uniformly on the structure, as well as the effective damping ratio is less than $20 \%$.

As the above mentioned discussion, to calculate the effective damping ratio, the dissipating energy of the absorber in a loading cycle and the total strain energy of the controlled structure under an expected interstory displacement need to be determined. Therefore, the equivalent additional damping ratio of an absorber attached to a structure is normally obtained as follows:
(1) Carry out the mechanical performance (hysteretic performance) test of the absorber. Obtain the energy dissipation capacity of the absorber under an expected displacement.

(2) Parameterize the hysteretic energy dissipation capacity of the damping device. Construct the finite element model of the controlled structure with the absorber.

(3) Perform the nonlinear time history analysis of the finite element model. Obtain the expected displacement of the structure with absorber, as well as the dissipating energy of the absorber under the expected displacement.

(4) Conduct the pushover analysis or the simplified theory calculation of the structure model with the 


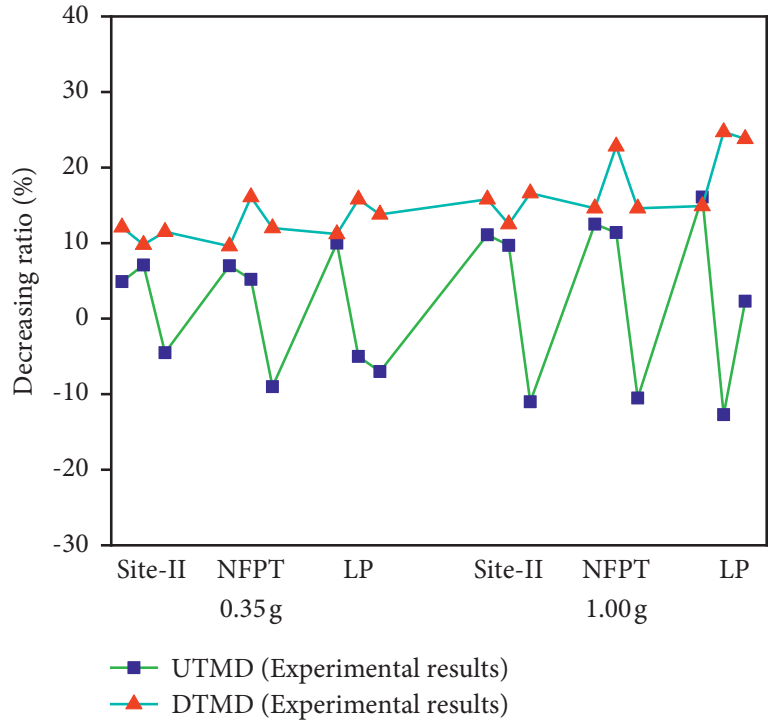

(a)

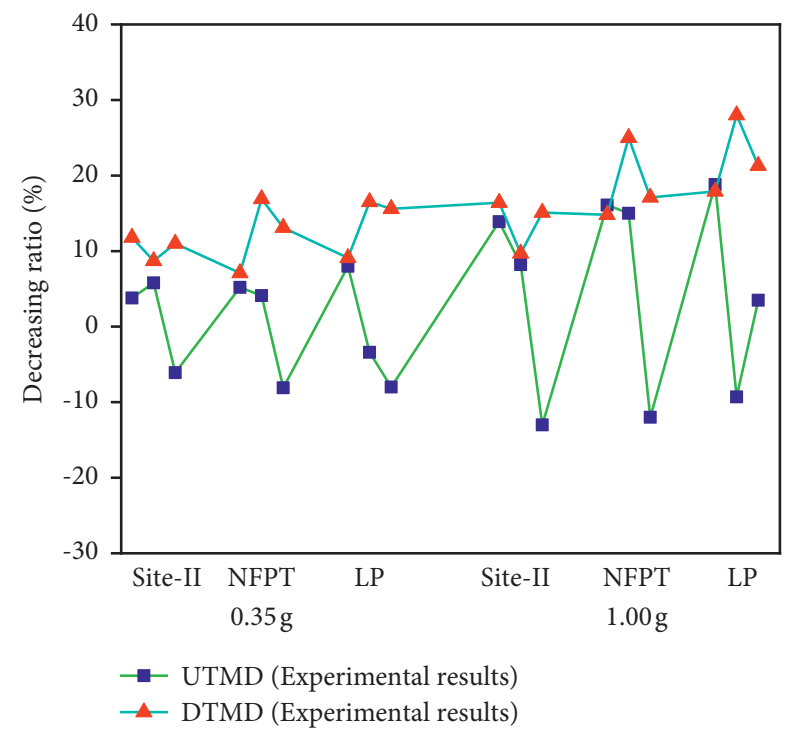

(b)

FIgURE 14: Comparison of the damping effect of the UTMD and the DTMD. (a) ADR. (b) AR.

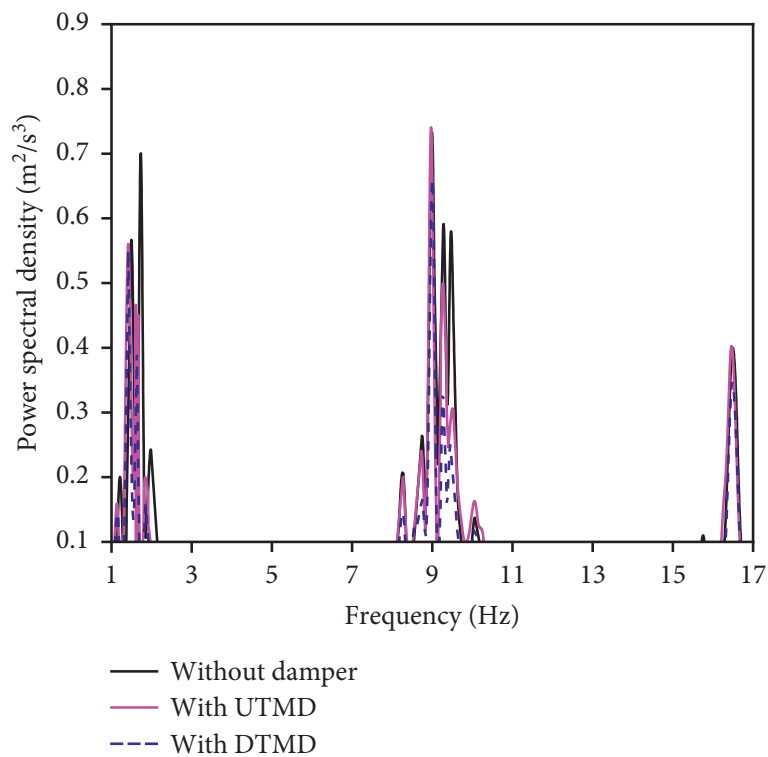

(a)

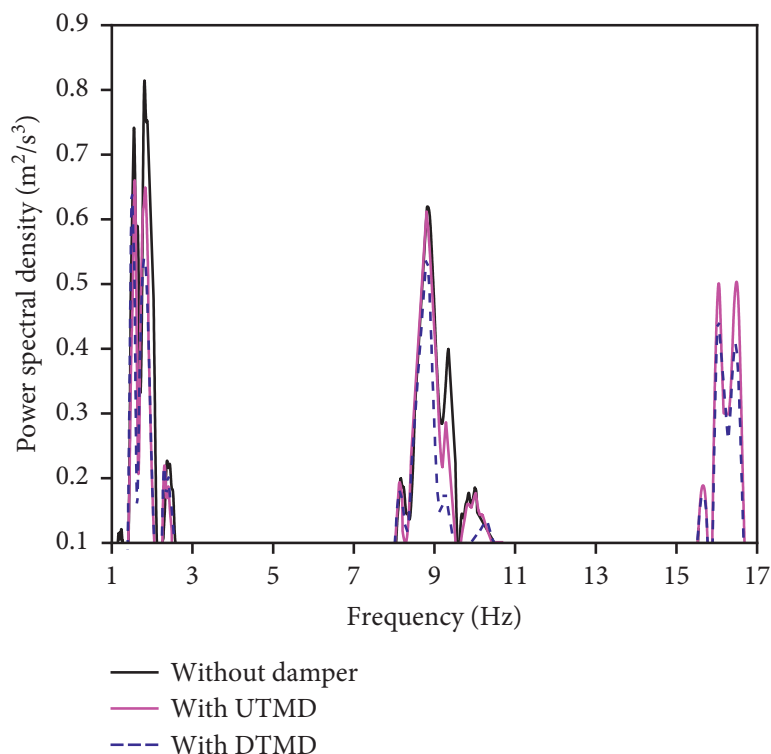

(b)

FIGURE 15: PSDs for accelerations of the model with the UTMD and the DTMD. (a) RSN69 (249). (b) RSN74.

absorber, and obtain the total strain energy of the controlled system under the expected displacement.

(5) Finally, calculate the additional effective damping ratio of the energy absorber by equation (15).

As we all know, the damping effect of tuned mass dampers (such as DTMD, TMD, and MTDM) is not only related to the tuning effect of the tuned mass (absorbed kinetic energy of the controlled structure) but also related to the energy dissipation of the damping device installed on it (dissipated kinetic energy of the controlled structure). There is energy exchange between the tuned mass damper and controlled structure during the whole vibration process. Therefore, under harmonic excitation, we can obtain the additional equivalent damping ratio of the tuned mass damper following the above procedure. However, under actual ground motions, the energy dissipation capacity of the tuned mass damper at an expected displacement is not uniform, which is related to the acceleration, velocity, and displacement time history of the system. And, the total strain energy of the system also cannot be obtained by a simple pushover or simplified calculation method (it is difficult to consider the contribution of the tuned mass damper to the system stiffness). Thus, the seismic design method of DTMD is still in the exploratory stage. 


\section{Conclusions}

In this study, a scale model of a typical high-rise structure was fabricated. Numerous excitations were chosen to clarify the dynamic responses of high-rise structures, including Site-II ground motions, NFPT ground motions with different velocity pulse periods, and LP ground motions. Then, based on minimising the peak displacement of a first $\mathrm{N}$-order vibration modal with a mass participation factor of $85 \%$, a parameter optimisation method was proposed for the DTMD. Furthermore, a DTMD with optimised parameters was designed and manufactured. Finally, a lot of shaking table tests were carried out for the scale model with and without the DTMD. The main findings of this study are as follows:

(1) The dynamic responses of high-rise structures under the LP and NFPT ground motions are significantly greater than those under Site-II ground motions. When the velocity pulse period of the NFPTs is close to the natural vibration period of the high-rise structure, the ADR, AR, and SR of high-rise structures are much more significant. Under an E2 earthquake excitation, the average amplitudes of the ADRs under LP and NFPT ground motions were 1.95 times and 1.51 times larger than those under Site-II ground motions, respectively. Moreover, the amplitudes of the SRs at the top floor of the structure reached $1646.60 \mu \varepsilon$ and $1331.92 \mu \varepsilon$ under LP and NFPT ground motions, respectively, i.e., much greater than those of the bottom floor $(239.40 \mu \varepsilon$ and $193.72 \mu \varepsilon)$.

(2) The optimised DTMD provides a wide damping frequency band and an excellent robustness. Larger excitation intensities will lead a better damping effect of the DTMD. However, the DTMD also has some damping capacity when the external excitation intensities are small. Under an E2 earthquake excitation, the average decreasing ratios of the ADR, RMSADR, AR, and SR are $15.0 \%, 14.5 \%, 13.7 \%$, and $14.5 \%$ under Site-II ground motions, respectively. The average decreasing ratios of the above four parameters are $17.3 \%, 20.4 \%, 19.0 \%$, and $17.5 \%$ under NFPT ground motions, respectively. The corresponding values are $21.1 \%, 23.7 \%, 22.4 \%$, and $22.1 \%$ under LP ground motions, respectively. The damping capacity of the DTMD under LP and NFPT ground motions is more significant than that under Site-II ground motions. Furthermore, the DTMD will provide a better damping effect when the velocity pulse period of the NFPT ground motion is close to the natural vibration period of the structure.

(3) The smaller damping ratio of the connection of the upper TMD will result in a better damping effect of the DTMD. An excessive damping ratio for this connection will induce the damper to become whole with the structure. Thus, the DTMD will not be able to respond adequately to the variations in the vibration state of the controlled structure. And, the damping capacity of the DTMD will decrease. The DTMD requires a certain excitation duration time to exert its damping control effect. In this study, when the excitation duration time is less than $0.5 \mathrm{~s}$, the dynamic response of the DTMD is relatively small. Therefore, the damping capacity of the DTMD cannot be fully realised. Further optimisation methods for decreasing the time delay of the DTMD damping effect will be the focus of future studies.

\section{Data Availability}

Data are available on request to the corresponding author.

\section{Conflicts of Interest}

The authors declare that they have no conflicts of interest.

\section{Authors' Contributions}

Botan Shen and Weibing Xu contribute equally to the article.

\section{Acknowledgments}

This study was partly supported by the National Natural Science Foundation of China (Grant nos. 51978021 and 51908015). The Beijing Municipal Education Commission (Grant nos. IDHT20190504 and KM201910005020) is greatly appreciated. This work was also supported by the National Key R\&D Program of China (Grant nos. 2017YFC1500604 and 2017YFE0103000). Their support is gratefully acknowledged.

\section{References}

[1] R. Enokida, T. Nagae, K. Kajiwara, M. Nakashima, and X. Ji, "Development of shaking table test techniques to realize large responses and evaluation of safety of a high-rise building," Journal of Structural \& Construction Engineering, vol. 74, no. 74, pp. 467-476, 2009.

[2] Y.-L. Chung, T. Nagae, T. Hitaka, and M. Nakashima, "Seismic resistance capacity of high-rise buildings subjected to long-period ground motions: e-defense shaking table test," Journal of Structural Engineering, vol. 136, no. 6, pp. 637-644, 2010.

[3] R. Sehhati, A. Rodriguez-Marek, M. Elgawady, and W. F. Cofer, "Effects of near-fault ground motions and equivalent pulses on multi-story structures," Engineering Structures, vol. 33, no. 3, pp. 767-779, 2011.

[4] I. Takewaki, K. Fujita, and S. Yoshitomi, "Uncertainties in long-period ground motion and its impact on building structural design: case study of the 2011 Tohoku (Japan) earthquake," Engineering Structures, vol. 49, no. 2, pp. 119-134, 2013.

[5] C. Tian, H. Zhang, C. Xiao, and J. Cao, "Experimental research on shaking table test of Shanghai Center tower," Building Structure, vol. 41, no. 11, pp. 47-52, 2011.

[6] G. Yang, W. Cao, H. Dong, W. Yang, and S. Tian, "Experimental study on eccentric compressive behavior of specialshaped multi-cavity mega-bifurcated concrete filled steel tubular columns," Journal of Building Structures, vol. 39, no. 6, pp. 41-52, 2018. 
[7] H. Wu and W. Cao, "Seismic performance of pentagonal concrete-filled steel tube megacolumns with different bottom constructions," The Structural Design of Tall and Special Buildings, vol. 28, no. 10, 2019.

[8] D. Zhou, J. Han, H. Yang et al., "Structural design of guangzhou tower," Building Structure, vol. 42, no. 6, pp. 1-12, 2012.

[9] D. Wang, D. Lu, L. Huang, J. Wang, L. Xu, and J. Zhu, "Structure design of jinta in tianjiin," Journal of Building Structures, vol. 30, no. S1, pp. 1-7, 2009.

[10] J.-g. Nie, Y.-h. Wang, and J.-s. Fan, "Experimental research on concrete filled steel tube columns under combined compression-bending-torsion cyclic load," Thin-Walled Structures, vol. 67, no. 2, pp. 1-14, 2013.

[11] Y. Wang, J. Fan, Y. Guo, and Y. Yang, "Loading capacity of steel reinforced concrete fish bone-shaped column," Journal of Tsinghua University, vol. 50, no. 6, pp. 810-814, 2010.

[12] B. Uy, Z. Tao, and L.-H. Han, "Behaviour of short and slender concrete-filled stainless steel tubular columns," Journal of Constructional Steel Research, vol. 67, no. 3, pp. 360-378, 2011.

[13] R. Tang, "Design of sightseeing tower in nanjing olympic Sports technology center," Progress in Steel Building Structures, vol. 11, no. 6, pp. 56-60, 2009.

[14] I. Venanzi, F. Ubertini, and A. L. Materazzi, "Optimal design of an array of active tuned mass dampers for wind-exposed high-rise buildings," Structural Control and Health Monitoring, vol. 20, no. 6, pp. 903-917, 2013.

[15] Z. Fan, K. Yang, H. Chai et al., "Structural design and research on beijing olympic tower," Journal of Building Structures, vol. 40, no. 3, pp. 106-117, 2019.

[16] M. Armali, H. Damerji, J. Hallal, and M. Fakih, "Effectiveness of friction dampers on the seismic behavior of high rise building VS shear wall system," Engineering Reports, vol. 1, no. 6, 2019.

[17] W. Liang, "Application of shear-type metal damper in a highrise project," Building Structure, vol. 49, no. S1, pp. 403-407, 2019.

[18] J. Qian and X. Ding, "Shaking table experiment study on the suppression dynamic response of a TV Tower with TLD," Journal of Building Structures, vol. 16, no. 5, pp. 32-39, 1995.

[19] W. Qu, B. Song, C. Yangui, and Z. Xinmin, "Design of controlled wind vibration response of the main building of Jinshan Mansion in Zhuhai with TLD," Journal of Building Structures, vol. 16, no. 3, pp. 21-28, 1995.

[20] Q. Jing, H. Li, L. Wang, and F. Li, "Wind-induced vibration control of International Trade Building of Dalian using tuned liquid dampers," Earthquake Engineering and Engineering Vibration, vol. 26, no. 2, pp. 111-118, 2006.

[21] F. Naeim, M. Lew, L. D. Carpenter et al., "Performance of tall buildings in Santiago, Chile during the 27 February 2010 offshore Maule, Chile earthquake," The Structural Design of Tall and Special Buildings, vol. 20, no. 1, pp. 1-16, 2011.

[22] Z. Lu, D. Wang, and Y. Zhou, "Experimental parametric study on wind-induced vibration control of particle tuned mass damper on a benchmark high-rise building," The Structural Design of Tall and Special Buildings, vol. 26, no. 8, Article ID 1359, 2017.

[23] L. Wang, W. Shi, Z. Ying, and Q. Zhang, "Semi-active eddy current pendulum tuned mass damper with variable frequency and damping," Smart Structures and Systems, vol. 25, no. 1, pp. 65-80, 2020.

[24] L. Wang, S. Nagarajaiah, W. Shi, and Y. Zhou, "Study on adaptive-passive eddy current pendulum tuned mass damper for wind-induced vibration control," The Structural Design of Tall and Special Buildings, vol. 29, no. 15, Article ID e1793, 2020.

[25] L. Wang, W. Shi, X. Li, Q. Zhang, and Y. Zhou, "An adaptivepassive retuning device for a pendulum tuned mass damper considering mass uncertainty and optimum frequency," Structural Control and Health Monitoring, vol. 26, no. 7, Article ID e2377, 2019.

[26] Q. Wang, H. Qiao, D. De Domenico, Z. Zhu, and Y. Tang, "Seismic response control of adjacent high-rise buildings linked by the Tuned Liquid Column Damper-Inerter (TLCDI)," Engineering Structures, vol. 223, Article ID 111169, 2020.

[27] G. Cai, F. Sun, J. Huang, and C. Wang, "Characteristic analysis of MTMD for seismically excited structures," Engineering Mechanics, vol. 17, no. 3, pp. 55-59, 2000.

[28] M. Gu, S. R. Chen, and C. C. Chang, "Parametric study on multiple tuned mass dampers for buffeting control of Yangpu Bridge," Journal of Wind Engineering and Industrial Aerodynamics, vol. 89, no. 11-12, pp. 987-1000, 2001.

[29] W. Tu and Y. Zou, "Analysis of multistory structures with MTMD in frequency domain," Engineering Mechanics, vol. 20, no. 3, pp. 78-88, 2003.

[30] M. Shahrouzi, G. Nouri, and N. Salehi, "Optimal seismic control of steel bridges by single and multiple tuned mass dampers using charged system search," International Journal of Civil Engineering, vol. 15, no. 2, pp. 309-318, 2017.

[31] C. Li, "Multiple active-passive tuned mass dampers for structures under the ground acceleration," Earthquake Engineering \& Structural Dynamics, vol. 32, no. 6, pp. 949-964, 2003.

[32] T. P. Bandivadekar and R. S. Jangid, "Dual-layer multiple tuned mass dampers for vibration control of structures," International Journal of Advanced Structural Engineering, vol. 2, no. 2, pp. 91-113, 2010.

[33] A. Tharwat and Sakr, "Vibration control of buildings by using partial floor loads as multiple tuned mass dampers," HBRC Journal, vol. 13, no. 2, pp. 133-144, 2017.

[34] L. Wang, W. Shi, Q. Zhang, and Y. Zhou, "Study on adaptivepassive multiple tuned mass damper with variable mass for a large-span floor structure," Engineering Structures, vol. 209, Article ID 110010, 2020.

[35] D. De Domenico, H. Qiao, Q. Wang, Z. Zhu, and G. Marano, "Optimal design and seismic performance of Multi-Tuned Mass Damper Inerter (MTMDI) applied to adjacent high-rise buildings," The Structural Design of Tall and Special Buildings, vol. 29, no. 14, Article ID e1781, 2020.

[36] C. Li, B. Han, and D. Du, "Control strategy of double tuned mass dampers for structures," China Civil Engineering Journal, vol. 38, no. 5, pp. 1-9, 2005.

[37] F. Teng, W. Yan, and W. Xu, "Analysis of papameters of Double Tuned Mass Damper and its design method for multidegree-of-freedom structures," Industrial Construction, vol. 44, no. S1, pp. 309-312, 2014.

[38] M. Ni, W. Yan, W. Xu, and J. Wang, "Fundamental characteristics of a double-tuned mass damper under simpleharmonical excitations," Journal of Vibration and Shock, vol. 34, no. 17, pp. 213-219, 2015.

[39] T. Wang, Civil Engineering Structural Test, Wuhan University Press, Wuhan, China, (in Chinese), 2014.

[40] W. Yan, J. Wang, H. Jia, W. Xu, and Y. Chen, "Parameter optimization method for tuned particle dampers and its effectiveness evaluation," Journal of Vibration and Shock, vol. 35, no. 7, pp. 145-151, 2016. 
[41] T. Chandrasekhara and R. Debbarma, "Seismic vibration control of skew bridges using multiple tuned mass dampers," International Journal of Engineering Technology, Management and Applied Sciences, vol. 4, pp. 16-28, 2016.

[42] T. T. Soong and G. F. Dargush, Passive Energy Dissipation Systems in Structural Engineering, Wiley \& Sons, Incorporated, John, Hoboken, NJ, US, 1997.

[43] R. Rana and T. T. Soong, "Parametric study and simplified design of tuned mass dampers," Engineering Structures, vol. 20 , no. 3, pp. 193-204, 1998.

[44] C. Li, "Performance of multiple tuned mass dampers for attenuating undesirable oscillations of structures under the ground acceleration," Earthquake Engineering \& Structural Dynamics, vol. 29, no. 9, pp. 1405-1421, 2000.

[45] C. Li and Y. Liu, "Optimum multiple tuned mass dampers for structures under the ground acceleration based on the uniform distribution of system parameters," Earthquake Engineering \& Structural Dynamics, vol. 32, no. 5, pp. 671-690, 2003.

[46] I. Halperin, Y. Ribakov, and G. Agranovich, "Optimal viscous dampers gains for structures subjected to earthquakes," Structural Control and Health Monitoring, vol. 23, no. 3, pp. 458-469, 2016.

[47] B. Shen, W. Xu, J. Wang et al., "Seismic control of super highrise structures with double-layer tuned particle damper," Earthquake Engineering \& Structural Dynamics, vol. 50, no. 3, pp. 791-810, 2021.

[48] W. Xu, Z. Luo, W. Yan, Y. Chen, and J. Wang, "Impact of pulse parameters on the seismic response of long-period bridges," Structure and infrastructure Engineering, vol. 16, no. 10, pp. 1461-1480, 2020.

[49] National Standard of People's Republic of China, Code for Seismic Design of Buildings (GB 50011-2010), China Architecture \& Building Press, Beijing, China, 2010. 